OPEN ACCESS

Edited by:

Chao Ni,

Zhejiang University, China

Reviewed by: Richa Shrivastava,

Birla Institute of Technology and Science, India

Carmen Veríssima Ferreira Halder,

State University of Campinas, Brazil

*Correspondence.

Yanru Qin

yanruqin@zzu.edu.cn

tThese authors have contributed equally to this work and share first

authorship

Specialty section:

This article was submitted to Molecular and Cellular Oncology, a section of the journal Frontiers in Cell and Developmental Biology

Received: 24 March 2021

Accepted: 27 July 2021

Published: 26 August 2021

Citation:

Wang L, Han H, Wang Z, Shi L, Yang M and Qin Y (2021) Targeting the Microenvironment in Esophageal

Cancer.

Front. Cell Dev. Biol. 9:684966. doi: 10.3389/fcell.2021.684966

\section{Targeting the Microenvironment in Esophageal Cancer}

\author{
Lei Wang ${ }^{1,2+}$, Huiqiong Han ${ }^{1,2+}$, Zehua Wang ${ }^{1,2}$, Litong Shi ${ }^{1,2}$, Mei Yang ${ }^{1,2}$ and Yanru Qin ${ }^{1,2 *}$ \\ ${ }^{1}$ Department of Oncology, The First Affiliated Hospital of Zhengzhou University, Zhengzhou, China, ${ }^{2}$ State Key Laboratory \\ of Esophageal Cancer Prevention and Treatment, Zhengzhou University, Zhengzhou, China
}

Esophageal cancer (EC) is the eighth most common type of cancer and the sixth leading cause of cancer-related deaths worldwide. At present, the clinical treatment for EC is based mainly on radical surgery, chemotherapy, and radiotherapy. However, due to the limited efficacy of conventional treatments and the serious adverse reactions, the outcome is still unsatisfactory (the 5-year survival rate for patients is less than 25\%). Thus, it is extremely important and urgent to identify new therapeutic targets. The concept of tumor microenvironment (TME) has attracted increased attention since it was proposed. Recent studies have shown that TME is an important therapeutic target for EC. Microenvironment-targeting therapies such as immunotherapy and antiangiogenic therapy have played an indispensable role in prolonging survival and improving the prognosis of patients with EC. In addition, many new drugs and therapies that have been developed to target microenvironment may become treatment options in the future. We summarize the microenvironment of EC and the latest advances in microenvironment-targeting therapies in this review.

Keywords: esophageal cancer, tumor microenvironment, vascular endothelial growth factor, PD-1/PD-L1, cancer associated fibroblasts

\section{INTRODUCTION}

Esophageal cancer (EC) is one of the most common malignancies and is a major global health challenge. In 2018, new cases of EC accounted for 3.2\% of the total cancer cases and EC-related deaths accounted for 5.3\% of the total cancer deaths (Bray et al., 2018; Wang L. et al., 2021). EC consists of two main pathologies-esophageal squamous cell carcinoma (ESCC) and esophageal adenocarcinoma (EAC). ESCC is the most common, mainly in East Asia and Africa, while EAC is mainly prevalent in North America and Europe (Arnold et al., 2015; Torre et al., 2015). Geographical distribution of EC is associated with diet and genetics (Smyth et al., 2017). More than half of patients with EC are often at an advanced stage when first diagnosed, and extensive metastasis makes radical surgery, which is currently the only cure for EC, impossible (Ohashi et al., 2015). At present, the treatment for advanced EC include chemotherapy, radiotherapy, and a few targeted drugs. Although great strides have been made in diagnosis and treatment, the 5-year survival rate for patients with advanced EC is still very poor; no more than 25\% (Enzinger and Mayer, 2003). The high mortality rate in EC patients indicates that better treatment methods and targets are needed.

The "seed and soil" hypothesis proposed by Paget (1989) is the prototype for the tumor microenvironment (TME). Subsequent complementary studies have found that TME is composed of a variety of different cells and proteins, including immune cells, extracellular matrix (ECM), and 
tumor blood vessels (Polyak et al., 2009). In addition, TME has several important characteristics, including hypoxia, acidosis, chronic inflammation, and immunosuppression, which are associated with tumor proliferation, migration, apoptosis, immune evasion, and angiogenesis (Sung and Chung, 2002; Whiteside, 2008). Moreover, TME is not invariant, but involves constant remodeling of cells and their secretions to make them more suitable for tumor survival (Han et al., 2020). This is partly responsible for the development of resistance to conventional treatments (Luan et al., 2021). All these indicate that the "soil" of EC is important for tumor survival and may be an avenue for overcoming neoplastic disease.

Cells in the microenvironment have better gene stability, suggesting that TME-targeted treatments may have better effects and lower chances of drug resistance. To date, the most popular therapies targeting TME in EC include antiangiogenic therapy (anti-VEGF) and immunotherapy (PD-1/PD-L1 inhibitors) (Kojima et al., 2020; Yang Y. M. et al., 2020; Zhang B. et al., 2020). Both monotherapy and combination therapies further improved treatment efficacy and prolonged survival in patients with EC. In addition, anti-inflammatory reoxygenation combined with radiotherapy or photodynamic therapy, tumor vaccine, blocking microenvironment signal transduction, and other new therapies prevent occurrence and improve the prognosis of EC (Huang and Fu, 2019; Liu J. et al., 2020; Yamamoto and Kato, 2020; Yang Y. M. et al., 2020). Moreover, many cells and factors in the microenvironment can be used as important indicators to judge the prognosis of EC (Lin et al., 2016; Han et al., 2020). This review summarizes the EC microenvironment and related targeted therapies.

\section{SUPPRESSING INFLAMMATION PREVENTS ESOPHAGEAL CANCER}

The relationship between inflammation and cancer has been a key focus of research, and long-term inflammatory stimulation is an important inducer of EC (Coussens and Werb, 2002). The EC microenvironment is filled with a variety of proinflammatory cytokines and inflammatory substances, all of which are closely associated with tumor occurrence, proliferation, and migration (Bhat et al., 2021). Systematic activation of inflammatory pathway signals promotes the progression of EC. Nuclear factor-kappa B (NF- $\kappa$ B) consists of a family of structurally related transcription factors (Zhang et al., 2019), and its elevated expression is considered a marker of inflammationinduced tumorigenesis (Karin et al., 2002; Izzo et al., 2006). In addition to the NF- $\kappa \mathrm{B}$ signaling pathway, interleukin-6 (IL6)/STAT3 signaling pathway was also found to be upregulated in EC (Wang et al., 2004; Groblewska et al., 2012a). IL-6 is a cytokine that signals by binding to gp130 via its receptor, IL-6R $\alpha$, to trigger downstream pathways and activate important molecules such as Ras-MAPK, SHP2, PI3K, STAT1, and STAT3. Activation of these pathways gives tumor cells the ability to survive in a highly toxic inflammatory environment and inhibits the effects of immunotherapy (Karin et al., 2002; Hodge et al., 2005).
There are several differences in the inflammatory microenvironment of ESCC and EAC. ESCC is the most common pathological type of EC in East Asia (Smyth et al., 2017), and several well-known carcinogenic factors, such as alcohol and smoking (Enzinger and Mayer, 2003; Rustgi and El-Serag, 2014), cause chronic irritation and subsequent inflammation of the esophageal epithelium through direct toxic effects and reactive oxygen species (ROS) production (Radojicic et al., 2012; Kubo et al., 2014). Epidemiological studies of high-risk populations in China have found that frequent consumption of superheated foods also increases the incidence of ESCC, which is thought to damage the esophageal epithelium and lead to increased inflammation (Shen et al., 2020). Thus, there is little doubt that chronic inflammation is a risk factor for ESCC. Barrett's esophagus is a precancerous lesion of EAC in which chronic gastroesophageal reflux (GERD) causes esophageal epithelial cells to be replaced by goblet cells (Dvorak et al., 2007). Gastric acid reflux directly damages the esophagus and promotes ROS production. Direct injury can trigger sonic hedgehog $(\mathrm{SHH})$ signaling between the damaged epithelium and adjacent stroma, leading to intestinal metaplasia (Wang et al., 2010). Infiltrating inflammatory cells also produce high quantities of ROS to promote epithelial cell transformation and the production of ROS directly leads to DNA damage, causing tumor-initiation mutations (Poulsen et al., 1998; Farhadi et al., 2002). Epidemiological studies have linked obesity to EC (Kamat et al., 2009; Rustgi and El-Serag, 2014). Obesity is in fact a systemic inflammation and a metabolic disorder, which is thought to play an important role in the origin of malignant diseases (Bianchini et al., 2002). There are several mechanisms that can explain the association between obesity and EC, including increased incidence of GERD, increased secretion of proinflammatory adipocytokines in the serum, causing insulin and insulin-like growth factor secretion disorder, and leptin (Eusebi et al., 2012; Greer et al., 2012; Mokrowiecka et al., 2012). In addition to obesity, microbes are also important factors. The imbalance in the oral and intestinal flora can lead to inflammation and gastroesophageal reflux. Based on analysis of high-risk populations, this imbalance is mainly manifested as a decrease in gram-positive bacteria and an increase in gram-negative bacteria (Yang L. et al., 2012; Walker and Talley, 2014).

Normal cells are more likely to mutate in an environment filled with inflammatory cells and cytokines, leading to the development of tumors (Coussens and Werb, 2002). Therefore, anti-inflammatory therapy is a very effective preventive measure. Primary prevention of EC involves improving lifestyle, that is, keeping away from the risk factors for inflammation, including avoiding smoking, consuming moderate quantities of alcohol, and maintaining a healthy weight. For patients with esophagitis or Barrett's esophagus, secondary prevention includes medication with proton pump inhibitors (PPIs) and prokinetics (e.g., Domperidone and Itopride). Anti-reflux surgery is also a form of primary prophylaxis. Some meta-analyses and cohort studies have shown that patients with Barrett's esophagus who were treated with PPIs had a lower incidence of dysplasia and EAC compared with those patients who were not treated with PPIs 
(Nguyen et al., 2009; Kastelein et al., 2013). Several drugs have also been shown to inhibit the production of inflammatory factors, thereby inhibiting inflammation. Curcumin, which is found in the household spice turmeric, can inhibit acid-induced IL- 6 and IL-8 production by inhibiting activation of the MAPK and PKC signaling pathways, as well as NF- $\kappa \mathrm{B}$ (Rafiee et al., 2009). This drug is expected to treat esophagitis caused by GERD. In addition to prevention, inhibition of inflammation can increase the sensitivity of radiation and chemotherapy in vivo and in vitro and forms one approach for comprehensively treating EC (Li et al., 2018; Liao et al., 2020).

\section{ANTI-ANGIOGENESIS IS A CLASSIC MICROENVIRONMENT-TARGETING THERAPY}

Angiogenesis plays an essential role in the development of most solid tumors, including EC, by delivering oxygen and nutrients to the tumor. Tumor angiogenesis is regulated by a variety of angiogenic factors such as vascular endothelial growth factor (VEGF), hepatocyte growth factor (HGF), transforming growth factor-beta (TGF- $\beta$ ), and hypoxia-inducible factor- 1 (HIF-1) (Ladeira et al., 2018). Hypoxia, acidosis, and nutritional deficiency can all upregulate the expression of VEGF and promote angiogenesis. Distant metastasis through blood vessels is an additional pathway for tumor progression. As early as Folkman (1971) speculated that blocking tumor blood vessels could inhibit tumor growth. Anti-angiogenic therapies, particularly VEGF inhibitors, have gradually improved following years of research and have played an important role in clinical treatment.

The key mediator of angiogenesis is VEGF, including VEGF$\mathrm{A} / \mathrm{B} / \mathrm{C} / \mathrm{D} / \mathrm{E}$ and placental growth factor (PIGF) (Roskoski, 2007). As shown in Figure 1, activation of VEGF/VEGFR and VEGF/NRP pathways not only promote the proliferation of vascular endothelial cells and accelerate angiogenesis but also play an important role in promoting lymphangiogenesis (Ding et al., 2006). VEGFR is also expressed in tumor cells. The binding of VEGF to VEGFR triggers multiple downstream signaling pathways, such as ERK1/2 and PI3K/Akt, to promote cell proliferation (Olsson et al., 2006; Chrzanowska-Wodnicka et al., 2008). Therefore, the VEGF/VEGFR signaling pathway is an effective target for the treatment of EC. A variety of VEGF/VEGFR inhibitors have been developed, including anlotinib, apatinib, sorafenib, sunitinib, ramucirumab, and bevacizumab (Table 1). Of these, anlotinib, apatinib, sorafenib, and ramucirumab have been shown to have clinical benefits in patients with EC during clinical trials (Wilke et al., 2014; Xu et al., 2014; Janjigian et al., 2015; Moehler et al., 2016; Cunningham et al., 2017; Liu G. et al., 2020; Yang Y. M. et al., 2020; Huang et al., 2021). The positive effect of Endostar combined with radiotherapy and chemotherapy in the treatment of ESCC has been reported and similar clinical trials are ongoing (Xu et al., 2014). Anlotinib and apatinib are included in the Chinese Society of Clinical Oncology (CSCO)-EC guidelines as important treatments for EC. Ramucirumab is also included in the National
Comprehensive Cancer Network (NCCN) guidelines for the treatment of gastroesophageal junction (GEJ) adenocarcinoma (Bang et al., 2020). In addition to monotherapy, combination with chemotherapy, immunotherapy, or radiotherapy can result in a better curative effect. Researchers successfully treated a patient with advanced ESCC using apatinib in combination with the PD-1 inhibitor camrelizumab (Yan et al., 2020). Li et al. (2019) showed that the combined use of apatinib and docetaxel significantly prolonged patients' survival and had controllable side effects. Currently, additional studies are exploring the use of combinations of anti-angiogenesis therapy and traditional therapies such as radiotherapy and chemotherapy. On the other hand, tumor blood vessels are structurally and functionally abnormal. This abnormality makes effective drug delivery become difficult and creates an abnormal microenvironment (e.g., hypoxia) that reduces the effectiveness of radiotherapy and chemotherapy. Researchers have found that using anti-angiogenic drugs can induce normalization of blood vessels, then making patients more sensitive to chemotherapy (Batchelor et al., 2007).

However, anti-angiogenesis therapy has some limitations. In addition to several manageable side effects such as hypertension, renal dysfunction, thrombosis, and woundhealing complications, anti-angiogenic drugs are suspected of affecting the spread of other chemotherapeutic drugs in vivo (Ye, 2016). Using positron emission tomography (PET), Van der Veldt and others observed that anti-angiogenic drugs could inhibit the delivery of cytotoxic drugs to the tumor site (Van der Veldt et al., 2012). This is not consistent with our previous theory that anti-angiogenic therapy induces structural and functional changes in tumor blood vessels that make them more similar to normal blood vessels, leading to increased blood flow and easier access of cytotoxic drugs into tumors (Batchelor et al., 2007). Zhao et al. (2019) found that small doses of apatinib could regulate TME, alleviate hypoxia, and increase the number of $\mathrm{T}$ cells at tumor sites, then enhance the efficacy of PD-1/PD-L1 inhibitors. Excessive doses do not have this effect. This theory has not yet been tested in EC, but it shows that adjusting the order and dosage of medication during treatment is necessary to obtain better efficacy. Current research suggests that anti-angiogenesis therapy combined with other treatments can achieve better therapeutic effects; thus, actively developing new angiogenesis inhibitors and exploring additional drug combination regimens is still the main focus of research efforts.

\section{MATURATION OF IMMUNOTHERAPY}

Immunotherapy may be the most significant breakthrough in the history of tumor treatment. In-depth study of the immune microenvironment of EC and accurate intervention has become a consensus among most people. The components of the immune microenvironment of EC are complex and diverse. As shown in Figure 2, tumor cells can inhibit the antitumor immune response by recruiting a variety of immune cell populations or expressing inhibitory molecular factors (Lin et al., 2016). Smart tumor cells disguise themselves and 


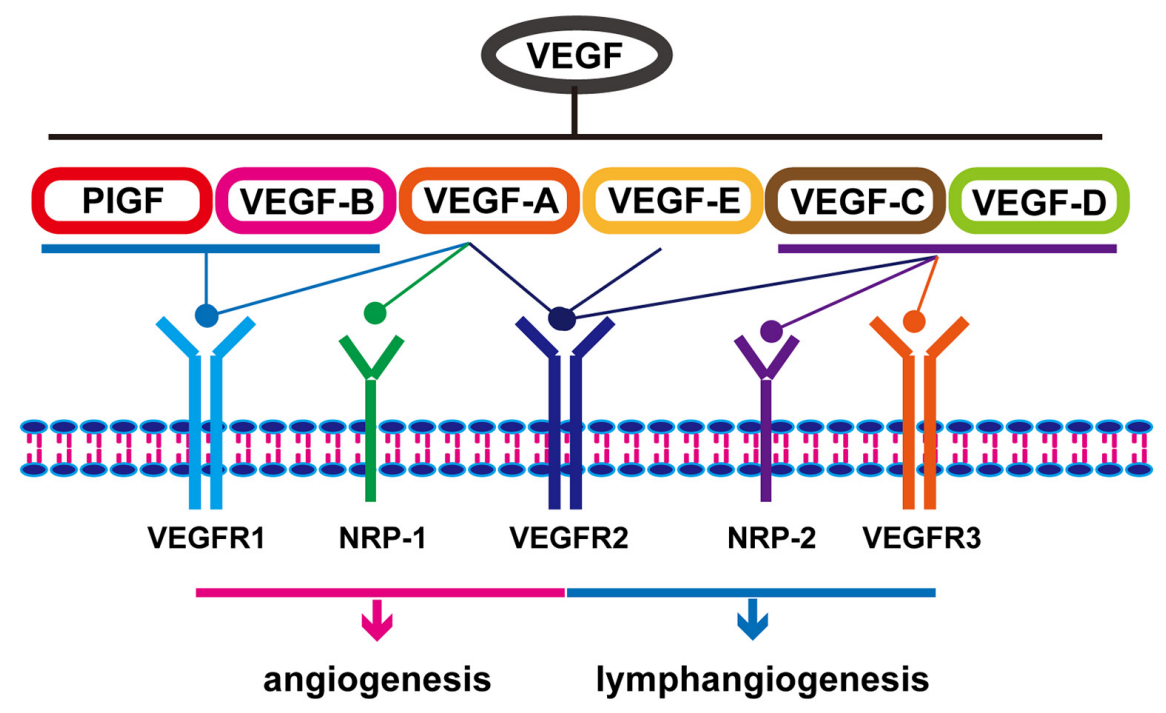

FIGURE 1 | Classification and function of vascular endothelial growth factors.

TABLE 1 | Vascular endothelial growth factor inhibitors applied to esophageal cancer.

\begin{tabular}{|c|c|c|c|c|c|c|}
\hline Molecule & NCT & Target & Strategy & Type & Result & References \\
\hline Bevacizumab & NCT00450203 & VEGF-A & Combination & EAC & Failure & Cunningham et al., 2017 \\
\hline \multirow[t]{3}{*}{ Ramucirumab } & NCT01170663 & VEGFR2 & Combination & GEJ & Success & Wilke et al., 2014 \\
\hline & NCT01246960 & VEGFR2 & Combination & EAC/GEJ & Failure & Yoon et al., 2016 \\
\hline & NCT02314117 & VEGFR2 & Combination & GEJ & Failure & Fuchs et al., 2019 \\
\hline \multirow[t]{2}{*}{ Sunitinib } & NCT00702884 & VEGFRs & Monotherapy & GEJ & Failure & Wu et al., 2015 \\
\hline & NCT00730353 & VEGFRs & Combination & EC/GEJ & Failure & Schmitt et al., 2012 \\
\hline \multirow[t]{2}{*}{ Sorafenib } & NCT00917462 & VEGFRs & Monotherapy & GEJ & Success & Janjigian et al., 2015 \\
\hline & NCT00253370 & VEGFRs & Combination & GEJ & Success & Sun et al., 2010 \\
\hline \multirow[t]{3}{*}{ Apatinib } & NCT03274011 & VEGFR2 & Monotherapy & ESCC & Ongoing & U.S. National Library of Medicine, $2021 \mathrm{a}$ \\
\hline & NCT03603756 & VEGFR2 & Combination & ESCC & Success & Zhang B. et al., 2020 \\
\hline & NCT02942329 & VEGFR2 & Combination & GEJ & Success & Xu et al., 2019 \\
\hline Anlotinib & NCT02649361 & VEGFRs & Monotherapy & ESCC & Success & Huang et al., 2021 \\
\hline Endostar & NCT03797625 & VEGFs & Combination & ESCC & Ongoing & U.S. National Library of Medicine, $2021 b$ \\
\hline
\end{tabular}

secrete a variety of cytokines to escape attack by $\mathrm{T}$ cells. Immunotherapy suppresses the expression of related pathways or provides immune system-specific tumor antigens that restore the immune system function and eliminates tumor cells. Mainstream immunotherapies include inhibition of immune checkpoints (PD-1/PD-L1), tumor vaccination, and adoptive T-cell therapy. These are described in detail below.

\section{Immune Checkpoint Blockade}

Programmed death-1 (PD-1) is an immune checkpoint for T cells that can deactivate their immune function. Two ligands, PD$\mathrm{L} 1$ and $\mathrm{PD}-\mathrm{L} 2$, bind to $\mathrm{PD}-1$ receptors, induce $\mathrm{PD}-1$ signal and associated T-cell depletion, and reversibly inhibit T-cell activation and proliferation (Zou et al., 2016). Activation of the PD-1/PDL1 signaling pathway can inhibit the function of CTL, while inhibition of this signaling pathway can restore $\mathrm{T}$ lymphocyte function and enhance the immune response (Chen and Mellman, 2017). Based on this principle, PD-1/PD-L1 blockers were developed for the treatment of tumors and have shown promise in the treatment of multiple malignancies (Topalian et al., 2012).

Programmed death- 1 inhibitors such as pembrolizumab and camrelizumab have recently been approved for the treatment of EC following extensive clinical trials. KEYNOTE-181 is a global multicenter, randomized, controlled, open, phase III clinical trial including 628 patients with advanced or metastatic EC. Final experimental results showed that, compared with chemotherapy, pembrolizumab prolonged overall survival when used as a second-line therapy for advanced EC in patients with PD-L1 $\geq 10$, with fewer treatment-related adverse events being reported (Kojima et al., 2020). In the latest KEYNOTE-590 study, pembrolizumab combined with cisplatinfluoropyrimidine chemotherapy as first-line therapy significantly improved overall survival in patients with EC compared with placebo (Smyth et al., 2021). Another PD-1 inhibitor invented in China, camrelizumab, was approved for the treatment of advanced ESCC in 2019 (Zhang B. et al., 2020). In addition to 


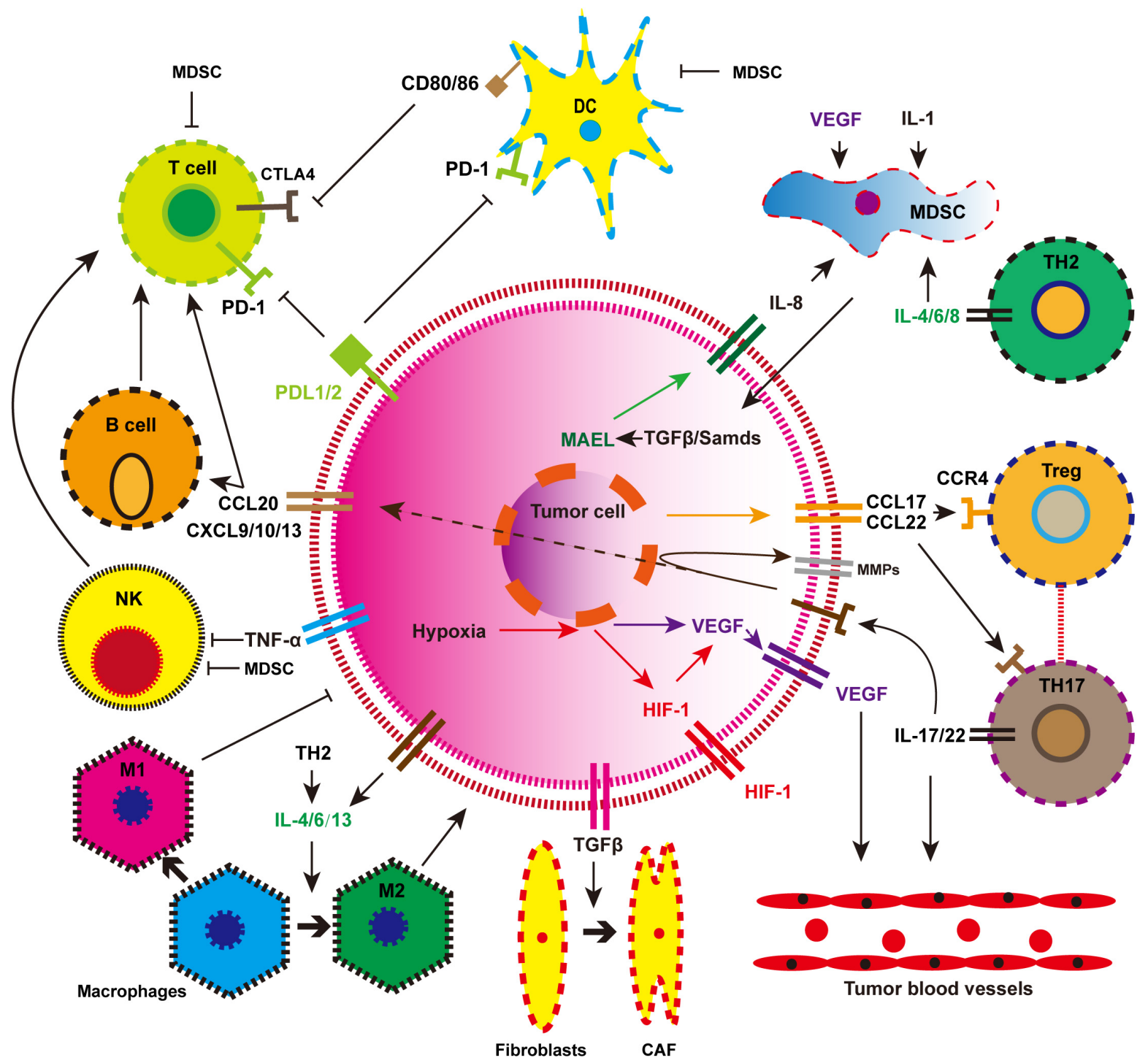

FIGURE 2 | The immune landscape of esophageal cancer. MDSC, myeloid-derived suppressor cell; DC, mature dendritic cell; NK, natural killer cell; Treg, regulatory T cell; M1, tumor suppressor macrophages; M2, tumor-promoting macrophages; CAF, cancer-associated fibroblasts.

the two PD-1 inhibitors mentioned above, there are multiple PD-1/PD-L1 inhibitors undergoing experimental verification, which will provide more options for immunotherapy in EC patients (Yamamoto and Kato, 2020). Compared with traditional chemotherapy, PD-1/PD-L1 inhibitors have fewer side effects and are more effective.

In clinical practice, most patients do not get better survival outcomes following the administration of PD-1 inhibitors. Therefore, predictive biomarkers are needed to determine whether patients are more likely to respond to PD-1/PDL1 inhibitors. In KEYNOTE-181, researchers found that, compared with chemotherapy, pembrolizumab significantly increased overall survival in PD-L1-positive patients. This may indicate that PD-L1 expression is a direct biological predictor. Disappointingly, PD-L1 status was not associated with objective response rates (ORR) in Chinese ESCC patients (Huang et al., 2018). Thus, we cannot predict therapeutic effect based only on the expression of PD-L1 in patients. Mismatch repair (MMR) defect, tumor mutation load (TML), and microsatellite instability (MSI) have been identified as predictive biomarkers in non-small cell lung cancer, but their role in EC needs to be validated (Yang H. et al., 2020). Li et al. (2021) recently found that upregulation of Laminin $\gamma 2(\operatorname{Ln}-\gamma 2)$ resulted in worse anti-PD-1 treatment outcome, which could be an effective biological predictor in the future. CAF-derived TGF- $\beta 1$ signaling leads to T-cell exclusion by increasing the expression of Ln$\gamma 2$ in ESCC cells, thereby constructing a protective barrier to the tumor, preventing immune cells from penetrating into tumor parenchyma, and weakening the response to anti-PD1 therapy. In addition, analysis of 260 patients with ESCC 
showed that $\operatorname{Ln}-\gamma 2$ is also an independent prognostic predictor. Furthermore, biometric analysis of several serological indicators and a variety of genes including HSPA6, CACYBP, DKK1, EGF, FGF19, GAST, OSM, and ANGPTL3 has also been implicated in having predictive significance (Guo et al., 2020). In fact, it is not very accurate to use a single indicator to predict the efficacy of immunotherapy. Lee and Ruppin found that comprehensive analysis of CD8 T-cell abundance, TML, and PD1 gene expression can give a more accurate prognosis (Lee and Ruppin, 2019). Whether the comprehensive use of the above indicators can accurately screen out immunotherapy-sensitive populations requires further exploration.

The expression of cytotoxic T-lymphocyte-associated antigen 4 (CTLA4) reduces T-cell activity by inhibiting T-cell receptor (TCR) signaling. A number of studies have shown that overexpression of CTLA4 can block the T-cell cycle, thereby reducing the body's specific immune function and leading to immune evasion of cancer cells (Krummel and Allison, 1995). Interestingly, CTLA4 is not only expressed by tumor infiltrating immune cells (TIICs) in EC, but is also expressed on cancer cells, which is an important part of tumor cell immune escape (Huang and Fu, 2019). Several studies have proven that CTLA4-targeted therapy can produce good survival benefits and fewer side effects. Currently available drugs for CTLA4 include ipilimumab and tremlimumab, of which tremlimumab has been proven to have a therapeutic effect on EC in clinical trials (Ralph et al., 2010). PD-1 and CTLA4 have different mechanisms for reducing $\mathrm{T}$-cell activation and the combined use of these two immune checkpoint inhibitors may yield better results. This synergistic effect (ipilimumab-nivolumab combination) has been demonstrated in melanoma; it is unproven but promising in EC (Weber et al., 2015).

\section{Cancer Vaccines}

Tumor-testicular antigens (TTA) are the most well-studied tumor-associated antigens (TAA) that are highly expressed in EC, including New York esophageal squamous cell carcinoma 1 (NY-ESO-1), melanoma-associated antigen-A (MAGE-A), TTK protein kinase (TTK), and Cancer-testis antigen 2 (CTAG2; also known as LAGE1) (Huang and Fu, 2019). Cancer vaccines induce an immune response through these specific antigens, stimulating CTLs to recognize and attack tumor cells. Several peptide vaccines are already in clinical trials (Kantoff et al., 2010; Kageyama et al., 2013). Cancer vaccines containing a combination of multiple peptides derived from TTK, lymphocyte antigen 6 complex locus K (LY6K), and insulin-like growth factor-II mRNA binding protein 3 (IMP3) were tested in phase II clinical trials for treatment of advanced EC (Kono et al., 2012). Results demonstrated that vaccine-induced immune responses in patients with advanced ESCC are associated with better outcomes, suggesting that tumor vaccine therapy using multiple epitope peptides as monotherapy may provide clinical benefits for EC patients. Another vaccine is DC vaccine pulsed with peptides. The powerful antigen-presenting function of DC cells enables the body to produce a stronger immune response which kills the tumor. Sadanaga et al. generated autologous DCs ex vivo and pulsed them with MAGE-3 peptide (Sadanaga et al., 2001).
This was the first report of DC vaccination of EC patients with MAGE-3 peptide. No toxicity was observed in vivo, and tumor regression was induced by an immune response to MAGE-3 peptide. At present, tumor vaccines are not formally used in clinical practice, but their strong and specific anti-tumor function requires further study.

\section{Chimeric Antigen Receptor T-Cell Therapy}

Chimeric antigen receptor- $\mathrm{T}$ cell therapy refers to the modification of $\mathrm{T}$ cells into chimeric antigen receptor (CAR) $\mathrm{T}$ cells through genetic engineering to specifically recognize and attack tumor cells. CAR-T cell therapy is more commonly used in hematologic tumors such as leukemia and lymphoma. In recent years, CAR- $T$ cells have been explored as a therapy against solid tumors, including EC (Kiesgen et al., 2018). Studies have shown that ephrin type A receptor 2 (EphA2) and human epidermal growth factor receptor 2 (HER2) are highly expressed in ESCC which are common targets for CAR-T cell therapies (Shi et al., 2018; Yu et al., 2020). Both CAR-T cell therapies have been demonstrated to effectively identify, bind, and destroy ESCC cell lines and release high levels of pro-inflammatory cytokines (Shi et al., 2018; Yu et al., 2020). Kagoya et al. (2018) recently designed a new generation of CAR-T cells with enhanced specificity, persistence, and anti-tumor ability by modifying the previous domain. Based on the CAR-T cell design described above, Zhang H. et al. (2020) designed enhanced MUC1-CAR-T cells for eliminating EC, which were shown to have significant antitumor activity. This enhanced MUC1-CAR-T cells have a longer survival time in mice, which means that they can have sustained anti-tumor ability. The enhanced CAR-T cells seem to be able to overcome the limitations of traditional CAR-T cells. The application of CAR-T cells in solid tumors still has certain limitations, including in the selection of solid tumor-specific antigens and the delivery of CAR-T cells (Akhoundi et al., 2021). Therefore, additional breakthroughs are needed in these areas.

\section{Oncolytic Viruses}

Recently, Challenor and Tucker (2021) reported the case of one patient with Hodgkin's lymphoma whose tumor disappeared after being infected with SARS-CoV-2. They hypothesized that the SARS-CoV-2 triggered a tumor immune response that allowed $\mathrm{T}$ cells to attack cancer cells. This is a special case, but it suggests that viral therapy may be effective. Oncolytic viruses are potential antitumor agents with unique therapeutic mechanisms, including the ability to directly lyse tumors and induce antitumor immunity. Since the first oncolytic virus (Talimogene laherparepvec) was approved for the treatment of melanoma, its use has been broadened, including in multiple experiments on EC (Andtbacka et al., 2015). Ma et al. (2012) confirmed that trichostatin enhanced the antitumor activity of oncolytic adenovirus H101 by activating the MAPK/ERK pathway. Another study used radiotherapy in combination with OBP-301, an attenuate type 5 adenovirus with oncolytic potential that contains the human telomerase reverse transcriptase 
promoter, to regulate viral replication, which is important for the treatment of EC (Kuroda et al., 2010).

\section{EXTRACELLULAR MATRIX AND SIGNAL TRANSDUCTION ACCELERATE TUMOR PROGRESSION}

The ECM is an important component of the TME, a network of proteins and glycosaminoglycan (Aguado et al., 2016; Hoshiba and Tanaka, 2016). ECM continues to be remodeled to adapt to the survival and progression of tumors. Easily occurring metastasis is one of the characteristics of malignant tumors and one of the reasons why tumors cannot be cured. Many studies have shown that the dynamic changes in ECM promote tumor metastasis.

\section{Stromal Components}

The most abundant component in ECM is type I collagen, which is secreted by tumor-associated fibroblasts (TAFs) or cancerassociated fibroblasts (CAFs), fills the gaps between cancer cells, and enhances the stiffness of the tumor (Kai et al., 2019). Dense ECM can inhibit the diffusion, penetration, and transportation of therapeutic drugs; thus, ECM becomes an obstacle to drug delivery (Cun et al., 2015; Jena et al., 2016). Another very important molecule is glycoproteins, which are involved in cellto-cell adhesion and which can be altered to facilitate migration of cancer cells (Palumbo et al., 2020). For example, deletion of E-cadherin, which is responsible for cell-cell adhesion and communication, has been shown to be associated with increased aggressiveness of tumor cells (Canel et al., 2013). Integrins are a family of transmembrane glycoprotein adhesion receptors that regulate extracellular matrix and cellular adhesion. Kwon et al. (2013) inhibited the proliferation and invasion of EC cells by knocking out integrin alpha 6 (ITGA6) in vitro, proving that ITGA6 could be a new therapeutic target. So, it is generally believed that the improvement in tumor stiffness and structure is directly associated with tumor invasion.

Remodeling of ECM is dependent on matrix degradable proteolytic enzymes, which mainly include matrix metalloproteinases (MMPs), plasminogen activators, atypical proteinases (e.g., intracellular cathepsin), and glycolytic enzymes (heparinase and hyaluronidase) (Piperigkou et al., 2021). MMPs are characterized by multi-domain zinc-dependent endopeptidases, which play an indispensable role in the continuous remodeling of ECM (Lei et al., 2020). Through ECM remodeling, MMPs regulate the proliferation, migration, and angiogenesis of tumor cells. More than 30 types of MMP have been identified, among which MMP-2 and MMP-9 are the most closely related to EC (Groblewska et al., 2012b). Overexpression of MMP-2 and MMP-9 results in poor prognosis in EC patients due to type IV collagen basement membrane rupture and is associated with advanced tumor stage, local invasion, and metastasis (Groblewska et al., 2012b). MMPs are regulated by their endogenous natural inhibitors (TIMPs), but in EC, this regulation mechanism is abnormal. The decrease in TIMPs expression and the increase in MMPs expression indicate poor prognosis in patients with EC (Groblewska et al., 2012b). Researchers are currently trying to synthesize exogenous MMP inhibitors (MMPIs) that inhibit tumor progression. Thanks to progress in drug technology, MMPIs now have higher specificity and lower toxic and side effects, and their related therapeutic effects have been verified in the treatments of periodontal disease, multiple sclerosis, and gastric cancer and may also be a new target for the treatment of EC (Fields, 2019). Another very important enzyme is lysyl oxidase (LOX), which catalyzes the cross-linking of collagen and elastin. Kalikawe et al. (2019) found that silencing LOX could inhibit the proliferation of ESCC cells and reduce their invasion and migration ability. Understanding the mechanism of these enzymes will benefit our clinical treatment.

Cancer-associated fibroblast is involved in the development of cancer (Figure 3). In Barrett's esophagus, reflux of stomach acid can stimulate the production of IL- 6 by esophageal fibroblasts and increase inflammation (Rieder et al., 2007). CAFs are activated by cytokines secreted by tumor cells such as TGF- $\beta$. More importantly, fibroblast-derived factor can induce esophageal epithelial metaplasia (Eda et al., 2003). CAFs can secrete a variety of important cytokines, including HGF, fibroblast growth factor (FGF), CXCL12, and TGF $\beta 1$, which play an important role in promoting the progression of EC. Subsequent studies confirmed that CAFs can also express VEGF, suggesting that it may be involved in EC angiogenesis (Nie et al., 2014). CAFs are also promoters of tumor invasion and metastasis. They produce factors such as Wnt2 that induce epithelial-mesenchymal transformation (EMT) of EC cells and thus increase cell motility (Fu et al., 2011). CAFs are strongly implicated in tumor progression; thus, eliminating CAFs as a way of inhibiting tumor progression may be a good idea. In vitro and animal model studies showed that EC cells co-cultured with CAFs were more prone to metastasis and that cell migration reduced after removal of CAFs (Kashima et al., 2019). In recent years, researchers have tried to inhibit tumor progression by eliminating or inhibiting CAFs. For example, near-infrared photoimmunotherapy (NIR-PIT) was proposed by Mitsunaga et al. (2011) as a new cancer treatment method using highly selective monoclonal antibody $(\mathrm{mAb})$-photosensitizer conjugate (APC). CAF elimination using CAF-targeted NIR-PIT effectively interferes with the progression of $\mathrm{EC}$ and overcomes therapeutic resistance (Katsube et al., 2021). Combining the new CAFtargeted NIR-PIT with traditional anticancer drugs is expected to provide a more effective treatment strategy.

\section{Important Signaling Pathways FGF/FGFR Pathway}

Fibroblast growth factors are known to play a crucial role in regulating excessive development during the embryonic and adult stages of life. When FGF binds to FGFRS, the downstream Ras-MAPK, PI3K-Akt, and PLC- $\gamma$-PKC pathways are activated, inducing cell proliferation, differentiation, and tumor formation (Liu G. et al., 2021). Analysis of the ESCC gene database showed that FGF12 expression was elevated, meaning that it can be used as a biomarker (Bhushan et al., 2017). Analysis 


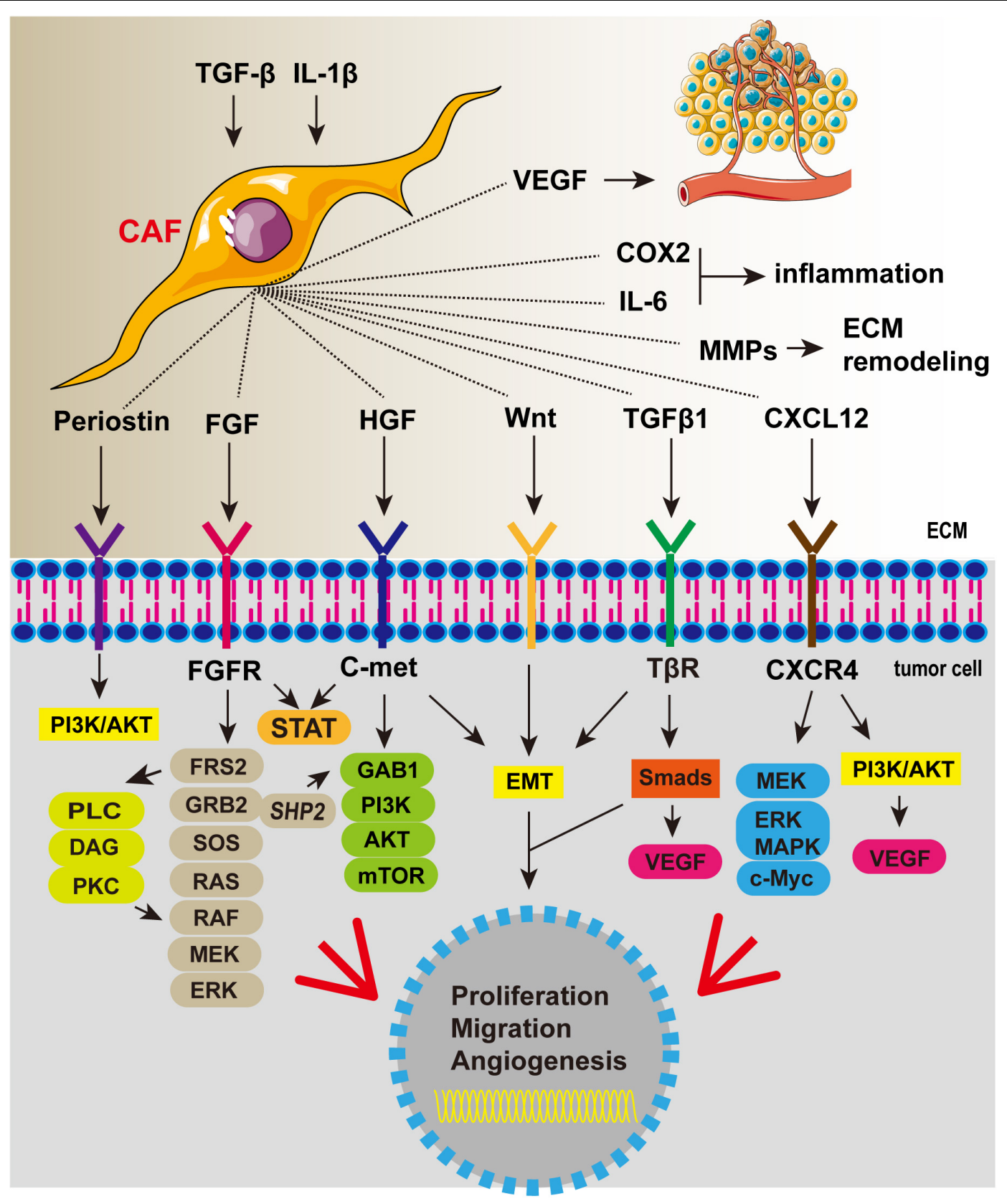

FIGURE 3 | Cancer-associated fibroblasts secrete a variety of cytokines that promote tumor proliferation, invasion, and angiogenesis and aggravate inflammation.

of ESCC samples also showed that the level of FGFR3IIIC, an FGF receptor, was elevated and tumor cell proliferation was increased (Ueno et al., 2016). In conclusion, systemic activation of the FGF/FGFR signaling pathway is important for the progression of EC. FGF/FGFR signaling plays a role in tumorigenesis, and a large number of drugs targeting this signaling pathway have been developed. Erdafitinib, a potent tyrosine kinase inhibitor of FGFR1/2/3/4, has been approved for the treatment of metastatic urothelial carcinoma (Loriot et al., 2019). Another FGFR inhibitor, pemigatinib, has also been shown to prolong survival in people with advanced cholangiocarcinoma
(Abou-Alfa et al., 2020). A phase 2 clinical trial in EC patients using brivanib (FGF and VEGF inhibitors) showed an objective therapeutic effect on gastroesophageal cancer, but the data was insufficient to support the application of this drug in clinical treatment (Jones et al., 2019). Additional data is therefore needed to verify the effectiveness of FGF/FGFR inhibitors in EC.

\section{HGF/c-Met Pathway}

The binding of HGF to its high-affinity receptor, c-Met, can initiate the proliferation, migration, and angiogenesis of various tumors and promote tumor progression (Wang et al., 2020). 
TABLE 2 | Factors and cells associated with poor esophageal cancer prognosis and their mechanisms of action.

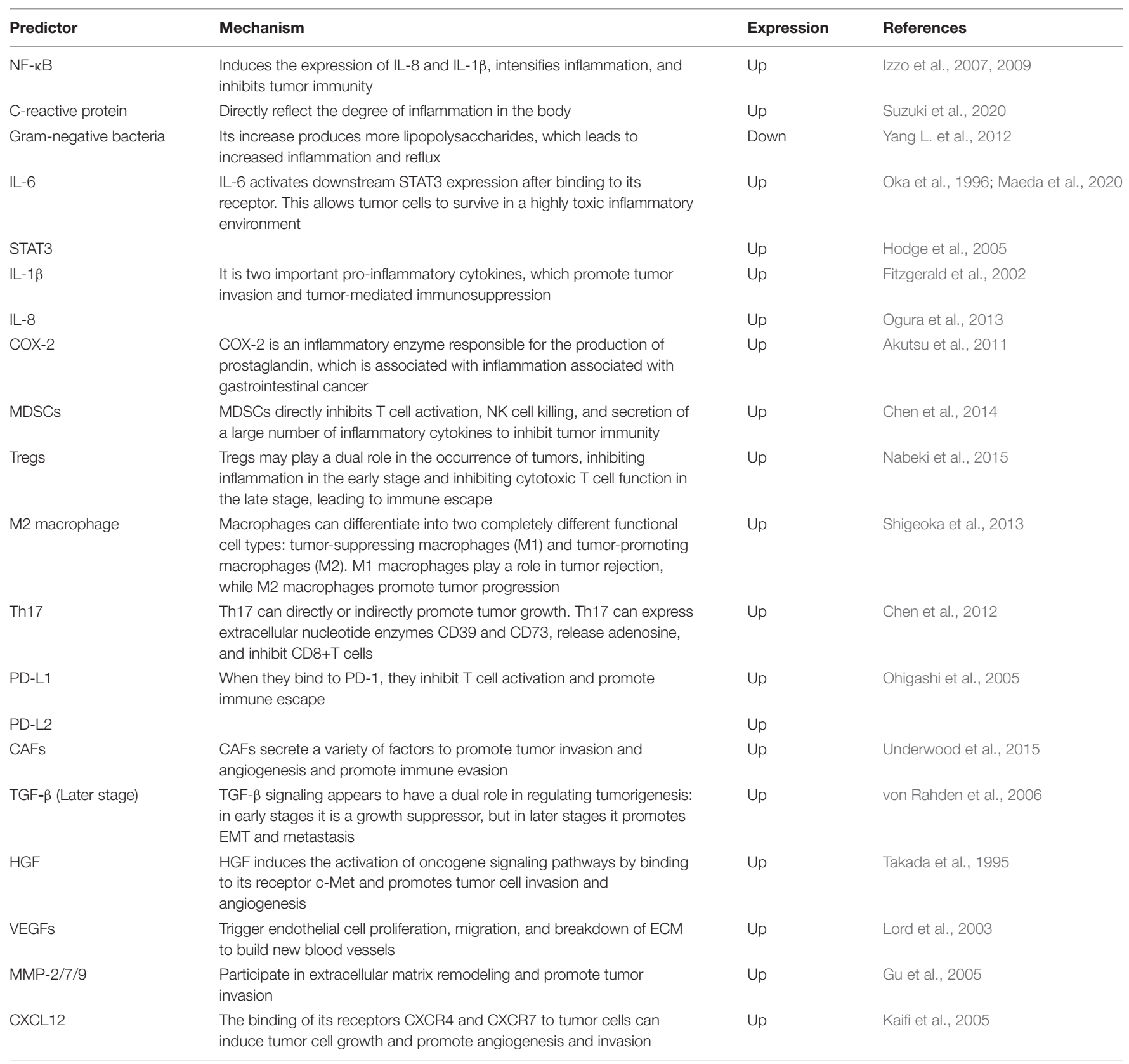

HGF secreted by mesenchymal cells is also considered an important angiogenic factor. It binds to c-Met (mainly expressed in epithelial cells) exclusively and induces the activation of oncogenic pathways, angiogenesis, and scattering of cells, leading to metastasis (Ladeira et al., 2018). Additionally, upregulation of the $\mathrm{HGF} / \mathrm{c}$-Met signaling pathway can lead to activation of the $\beta$-catenin and PI3K/Akt pathways and deactivation of the E-cadherin pathway, promoting tumor invasion (Anderson et al., 2006). Several HGF/c-Met inhibitors which inhibit downstream signaling by either blocking HGF binding to c-Met or directly targeting c-Met are currently in clinical trials. Obinutuzumab and rilotumumab are humanized monoclonal antibodies that target
HGF and inhibit its binding to c-Met (Shah et al., 2016; Catenacci et al., 2017). Unfortunately, using rilotumumab combined with cisplatin, capecitabine, and epirubicin as first-line treatment for MET-positive gastroesophageal adenocarcinoma did not give survival benefits (Catenacci et al., 2017). Obinutuzumab also failed in Phase III clinical trials. However, several c-Met inhibitors have been shown to be effective at inhibiting $\mathrm{HGF} / \mathrm{c}-\mathrm{Met}$ signaling by directly targeting c-Met. For example, AMG337, a highly selective small-molecule MET inhibitor, can effectively prevent c-Met/HGF binding. In a multi-center phase II study, AMG337, used as a single agent, showed significant anti-tumor activity in MET-amplified EAC patients 
(Van Cutsem et al., 2019). Additional data is needed to verify the effectiveness of HGF/c-Met inhibitors.

\section{TGF- $\beta$ Pathway}

Many studies have clarified the important role of TGF- $\beta$ in tumor regulation, including proliferation, angiogenesis, immune escape, and cell differentiation (Derynck et al., 2001). Interestingly, TGF$\beta$ plays a dual role in tumor progression, acting as a negative regulator in the early stage of tumor development but inducing epithelial mesenchymal transformation (EMT) and promoting migration in the late stages of development (Wojtowicz-Praga, 2003). Typically, TGF- $\beta$ blocks the normal cell cycle in the G1 phase by inhibiting c-Myc and increasing the expression of P21 and P15, which are considered major regulators of the cell cycle (Wang L. et al., 2021). Activation of TGF- $\beta /$ Smads inhibits the expression of cyclin-dependent kinase (CDK) inhibitors in advanced tumor cells and simultaneously activates the PI3K/Akt pathway, thereby preventing FoxO and Smad3 recombination. Ras/MAP kinases are also activated to induce EMT by bypassing TGF- $\beta$ inhibition (Haque and Morris, 2017). As mentioned above, activation of the TGF- $\beta$ signaling pathway can promote tumor progression and is therefore a potential therapeutic target. The most common inhibitors use the following mechanisms: (1) interferes with TGF- $\beta$ synthesis, (2) blocks TGF- $\beta$ signaling and downstream regulatory molecules, and (3) increases TGF$\beta$ endogenous or exogenous inhibitors. There are currently multiple TGF- $\beta$ inhibitors in clinical trials. For example, Galunisertib, a small molecule inhibitor that directly targets TGFBR1 kinase, has shown satisfactory therapeutic effects in phase I clinical trials of advanced liver, pancreatic, breast, and colorectal cancers (Ahmadi et al., 2019). Unfortunately, TGF$\beta$ inhibitors have not been reported for EC. Moreover, TGF$\beta$ 's complex regulatory signals and dual effects also present challenges in its targeted therapy. However, TGF- $\beta$ has shown anti-tumor effects in other cancer types, leading us to believe that it has great potential for use in the treatment of EC.

\section{IMPROVING THE HYPOXIC MICROENVIRONMENT}

Hypoxia and acidosis are common phenomena in a variety of solid tumors, including EC, and lead to a series of physiological changes. Tumor cells rapidly proliferate and consume large volumes of oxygen. In addition, solid tumors compress blood vessels around the tumor and cause blood vessel blockages, which results in insufficient oxygen supply to the center of the tumor (Masoud and Li, 2015; Bhattarai et al., 2018). Normally differentiated cells rely mainly on the oxidative phosphorylation of mitochondria to provide energy for the cells, while most tumor cells depend on aerobic glycolysis, a phenomenon called Warburg effect (Vander Heiden et al., 2009). This phenomenon exacerbates hypoxia and lactic acid accumulation in solid tumors and promotes tumor metastasis. Under hypoxic conditions, the functional inactivation of prolylhydroxylase 2 (PHD-2) leads to reduced degradation of HIF-1, which is an important regulator of hypoxic microenvironments
(Masoud and Li, 2015). Overexpression of HIF- $1 \alpha$ upregulates GLUTs, hexokinase isoform 2 (HK2), pyruvate kinase isoform M (PKM), and other key factors, leading to tumor aerobic glycolytic metabolism (Kato et al., 2018; Sormendi and Wielockx, 2018; Han et al., 2020). The phenomenon is also applicable to EC, where several important regulatory factors such as HIF-1 $\alpha$, GLUT-1, and PKM2 have been found to be elevated (Xiaoyu et al., 2018). Another endogenous hypoxia marker, Carbonic anhydrase IX (CAIX), is also overexpressed in EC (Jomrich et al., 2014). In addition, the increased expression of HIF- $1 \alpha$ can also directly upregulate VEGF and PD-L1, which are associated with tumor angiogenesis and immune escape, respectively (Augustin et al., 2020). In the hypoxic microenvironment, many immune cells are affected by HIF-1 $\alpha$, which reduces the immune response and promotes the proliferation of tumors. Moreover, hypoxia can also lead to genetic mutations that inhibit the effects of radiotherapy; downregulation of homologous recombinant proteins BRCA1 and BRCA2 in EC cells promoted G0-G1 cell cycle arrest and thus reduced the response to radiotherapy (Nguyen et al., 2013). A recent study using single-cell sequencing showed that HIF1 expression decreased in paclitaxel-resistant EC cells, but this phenomenon was reversed with carfilzomib (Wu et al., 2018).

Hypoxia is one of the characteristics of solid tumors and is therefore a potential therapeutic target. Several approaches have been targeted at the hypoxic microenvironment, including HIF- $1 \alpha$ targeted therapy, CAIX antagonists, nanomedicine, and traditional Chinese medicine (Wang et al., 2016; Wigerup et al., 2016; Chen et al., 2018; Li et al., 2018; Pan et al., 2018; Yu et al., 2018). Dihydroartemisinin, which is a derivative of artemisinin, can enhance the sensitivity of other treatments by inhibiting the expression of HIF-1 $\alpha$ (Li et al., 2018). Chinese herbal medicine has thus proved unique in improving the hypoxic microenvironment and treating EC, but the specific underlying mechanism still requires in-depth analysis. EC can also be treated using phototherapy (Wang B. et al., 2021; Xiang et al., 2021). Recently, Liu J. et al. (2020) designed a cage-like carbonmanganese nanozyme which can not only improve the hypoxic microenvironment but also deliver a lot of photosensitizers to the tumor site, making it useful for real-time tumor imaging and enhancing the efficacy of phototherapy. This new nanomedicine has been verified in both in vivo and in vitro experiments. Improving the hypoxic microenvironment is an essential part of treating EC. At present, there are few treatment methods targeting the hypoxic microenvironment of EC and most of them are still in preclinical studies.

\section{RELATIONSHIP BETWEEN MICROENVIRONMENT INDICATORS AND PROGNOSIS}

Multiple factors in the microenvironment play an indispensable role in EC development. Therefore, the detection of microenvironment indicators can predict the prognosis of patients to a certain extent. These prognostic indicators are summarized in Table 2. 


\section{CONCLUSION}

In this review, we summarized a variety of microenvironmenttargeted therapies. At present, traditional therapies such as surgery, chemotherapy, and radiotherapy are still the main treatments for EC. Due to the drug resistance and side effects of traditional treatment, the current therapeutic effect does not meet our requirements. In a recent review, Luan et al. (2021) detailed the relationship between microenvironment and drug resistance in EC, suggesting that microenvironmenttargeted therapy may be a breakthrough point for drug resistance. These results highlight the function of TME as a therapeutic target.

Some microenvironment-targeted drugs, such as PD-1/PD-L1 inhibitors and anti-angiogenesis drugs, have entered the clinic and shown good outcomes. New immunotherapies, such as CAR$\mathrm{T}$ therapy, tumor vaccines, and oncolytic viruses, are undergoing clinical trials and have demonstrated initial therapeutic value. In addition, inhibition of the inflammatory microenvironment and improvement of hypoxia are also helpful for patient outcomes. However, existing treatment regimens have many limitations and are not sufficient to cure malignancies; thus, additional research is needed. First, enhancing the effectiveness of existing drugs, e.g., using biomarkers to identify drug-sensitive patients or combining drugs to enhance efficacy, is the simplest way of extending patient survival. Second, many microenvironmenttargeted drugs that have shown significant anticancer effects in other tumors can also be used to treat EC. For example, TGF$\beta$ pathway inhibitors can not only directly inhibit the tumor but also enhance human immunity. Tests can be performed

\section{REFERENCES}

Abou-Alfa, G. K., Sahai, V., Hollebecque, A., Vaccaro, G., Melisi, D., Al-Rajabi, R., et al. (2020). Pemigatinib for previously treated, locally advanced or metastatic cholangiocarcinoma: a multicentre, open-label, phase 2 study. Lancet Oncol. 21, 671-684. doi: 10.1016/s1470-2045(20)30109-1

Aguado, B. A., Caffe, J. R., Nanavati, D., Rao, S. S., Bushnell, G. G., Azarin, S. M., et al. (2016). Extracellular matrix mediators of metastatic cell colonization characterized using scaffold mimics of the pre-metastatic niche. Acta Biomater. 33, 13-24. doi: 10.1016/j.actbio.2016.01.043

Ahmadi, A., Najafi, M., Farhood, B., and Mortezaee, K. (2019). Transforming growth factor- $\beta$ signaling: tumorigenesis and targeting for cancer therapy. J. Cell Physiol. 234, 12173-12187. doi: 10.1002/jcp.27955

Akhoundi, M., Mohammadi, M., Sahraei, S. S., Sheykhhasan, M., and Fayazi, N. (2021). CAR T cell therapy as a promising approach in cancer immunotherapy: challenges and opportunities. Cell Oncol. (Dordr.) 44, 495-523. doi: 10.1007/ s13402-021-00593-1

Akutsu, Y., Hanari, N., Yusup, G., Komatsu-Akimoto, A., Ikeda, N., Mori, M., et al. (2011). COX2 expression predicts resistance to chemoradiotherapy in esophageal squamous cell carcinoma. Ann. Surg. Oncol. 18, 2946-2951. doi: 10.1245/s10434-011-1645-z

Anderson, M. R., Harrison, R., Atherfold, P. A., Campbell, M. J., Darnton, S. J., Obszynska, J., et al. (2006). Met receptor signaling: a key effector in esophageal adenocarcinoma. Clin. Cancer Res. 12(20 Pt 1), 5936-5943. doi: 10.1158/10780432.Ccr-06- 1208

Andtbacka, R. H., Kaufman, H. L., Collichio, F., Amatruda, T., Senzer, N., Chesney, J., et al. (2015). Talimogene laherparepvec improves durable response rate in patients with advanced melanoma. J. Clin. Oncol. 33, 2780-2788. doi: 10.1200/ jco.2014.58.3377 on EC to determine drug efficacy. Finally, in addition to the targets mentioned above, there are many mechanisms of the microenvironment that are currently unknown. Further studies of these mechanisms and active research and development of new drugs are important for achieving breakthroughs in EC. We believe that microenvironment-targeted therapy can achieve greater survival benefits for patients with EC and its specific mechanism requires further exploration.

\section{AUTHOR CONTRIBUTIONS}

YQ designed the study and reviewed the manuscript. LW and $\mathrm{HH}$ participated in study design and wrote the original draft of the manuscript. LW was mainly responsible for the design of the image. ZW, LS, and MY were involved in document retrieval and review. All authors agreed to the submission of the final manuscript.

\section{FUNDING}

This study was supported by the National Natural Science Foundation of China (Grant No. 81872264).

\section{ACKNOWLEDGMENTS}

We acknowledge Haiyu Wang, Chi Qin, Longxiao Zhang, Haonan $\mathrm{Xu}$, and Hongyi Li for their support during this study.

Arnold, M., Soerjomataram, I., Ferlay, J., and Forman, D. (2015). Global incidence of oesophageal cancer by histological subtype in 2012. Gut 64, 381-387. doi: 10.1136/gutjnl-2014-308124

Augustin, R. C., Delgoffe, G. M., and Najjar, Y. G. (2020). Characteristics of the tumor microenvironment that influence immune cell functions: hypoxia, oxidative stress, metabolic alterations. Cancers (Basel) 12:3802. doi: 10.3390/ cancers 12123802

Bang, Y. J., Golan, T., Dahan, L., Fu, S., Moreno, V., Park, K., et al. (2020). Ramucirumab and durvalumab for previously treated, advanced non-smallcell lung cancer, gastric/gastro-oesophageal junction adenocarcinoma, or hepatocellular carcinoma: an open-label, phase Ia/b study (JVDJ). Eur. J. Cancer 137, 272-284. doi: 10.1016/j.ejca.2020.06.007

Batchelor, T. T., Sorensen, A. G., di Tomaso, E., Zhang, W. T., Duda, D. G., Cohen, K. S., et al. (2007). AZD2171, a pan-VEGF receptor tyrosine kinase inhibitor, normalizes tumor vasculature and alleviates edema in glioblastoma patients. Cancer Cell 11, 83-95. doi: 10.1016/j.ccr.2006.11.021

Bhat, A. A., Nisar, S., Maacha, S., Carneiro-Lobo, T. C., Akhtar, S., Siveen, K. S., et al. (2021). Cytokine-chemokine network driven metastasis in esophageal cancer; promising avenue for targeted therapy. Mol. Cancer 20:2. doi: 10.1186/ s12943-020-01294-3

Bhattarai, D., Xu, X., and Lee, K. (2018). Hypoxia-inducible factor-1 (HIF-1) inhibitors from the last decade (2007 to 2016): a "structure-activity relationship" perspective. Med. Res. Rev. 38, 1404-1442. doi: 10.1002/med.21477

Bhushan, A., Singh, A., Kapur, S., Borthakar, B. B., Sharma, J., Rai, A. K., et al. (2017). Identification and validation of fibroblast growth factor 12 gene as a novel potential biomarker in esophageal cancer using cancer genomic datasets. Omics 21, 616-631. doi: 10.1089/omi.2017.0116

Bianchini, F., Kaaks, R., and Vainio, H. (2002). Overweight, obesity, and cancer risk. Lancet Oncol. 3, 565-574. doi: 10.1016/s1470-2045(02)00849-5 
Bray, F., Ferlay, J., Soerjomataram, I., Siegel, R. L., Torre, L. A., and Jemal, A. (2018). Global cancer statistics 2018: GLOBOCAN estimates of incidence and mortality worldwide for 36 cancers in 185 countries. CA Cancer J. Clin. 68, 394-424. doi: 10.3322/caac.21492

Canel, M., Serrels, A., Frame, M. C., and Brunton, V. G. (2013). E-cadherinintegrin crosstalk in cancer invasion and metastasis. J. Cell Sci. 126(Pt 2), 393-401. doi: 10.1242/jcs.100115

Catenacci, D. V. T., Tebbutt, N. C., Davidenko, I., Murad, A. M., Al-Batran, S. E., Ilson, D. H., et al. (2017). Rilotumumab plus epirubicin, cisplatin, and capecitabine as first-line therapy in advanced MET-positive gastric or gastro-oesophageal junction cancer (RILOMET-1): a randomised, doubleblind, placebo-controlled, phase 3 trial. Lancet Oncol. 18, 1467-1482. doi: 10. 1016/s1470-2045(17)30566- 1

Challenor, S., and Tucker, D. (2021). SARS-CoV-2-induced remission of Hodgkin lymphoma. Br. J. Haematol. 192:415. doi: 10.1111/bjh.17116

Chen, D. S., and Mellman, I. (2017). Elements of cancer immunity and the cancer-immune set point. Nature 541, 321-330. doi: 10.1038/nature21349

Chen, D., Hu, Q., Mao, C., Jiao, Z., Wang, S., Yu, L., et al. (2012). Increased IL17-producing CD4(+) T cells in patients with esophageal cancer. Cell Immunol. 272, 166-174. doi: 10.1016/j.cellimm.2011.10.015

Chen, H., Liu, P., Zhang, T., Gao, Y., Zhang, Y., Shen, X., et al. (2018). Effects of diphyllin as a novel V-ATPase inhibitor on TE-1 and ECA-109 cells. Oncol. Rep. 39, 921-928. doi: 10.3892/or.2018.6191

Chen, M. F., Kuan, F. C., Yen, T. C., Lu, M. S., Lin, P. Y., Chung, Y. H., et al. (2014). IL-6-stimulated CD11b+ CD14+ HLA-DR- myeloid-derived suppressor cells, are associated with progression and poor prognosis in squamous cell carcinoma of the esophagus. Oncotarget 5, 8716-8728. doi: 10.18632/oncotarget.2368

Chrzanowska-Wodnicka, M., Kraus, A. E., Gale, D., White, G. C. II, and Vansluys, J. (2008). Defective angiogenesis, endothelial migration, proliferation, and MAPK signaling in Rap1b-deficient mice. Blood 111, 2647-2656. doi: 10.1182/ blood-2007-08-109710

Coussens, L. M., and Werb, Z. (2002). Inflammation and cancer. Nature 420, 860-867. doi: 10.1038/nature01322

Cun, X., Chen, J., Ruan, S., Zhang, L., Wan, J., He, Q., et al. (2015). A novel strategy through combining iRGD peptide with tumor-microenvironment-responsive and multistage nanoparticles for deep tumor penetration. ACS Appl. Mater. Interfaces 7, 27458-27466. doi: 10.1021/acsami.5b09391

Cunningham, D., Stenning, S. P., Smyth, E. C., Okines, A. F., Allum, W. H., Rowley, S., et al. (2017). Peri-operative chemotherapy with or without bevacizumab in operable oesophagogastric adenocarcinoma (UK Medical Research Council ST03): primary analysis results of a multicentre, open-label, randomised phase 2-3 trial. Lancet Oncol. 18, 357-370. doi: 10.1016/s1470-2045(17)30043-8

Derynck, R., Akhurst, R. J., and Balmain, A. (2001). TGF-beta signaling in tumor suppression and cancer progression. Nat. Genet. 29, 117-129. doi: 10.1038/ ng1001- 117

Ding, M. X., Lin, X. Q., Fu, X. Y., Zhang, N., and Li, J. C. (2006). Expression of vascular endothelial growth factor-C and angiogenesis in esophageal squamous cell carcinoma. World J. Gastroenterol. 12, 4582-4585. doi: 10.3748/wjg.v12.i28. 4582

Dvorak, K., Payne, C. M., Chavarria, M., Ramsey, L., Dvorakova, B., Bernstein, H., et al. (2007). Bile acids in combination with low $\mathrm{pH}$ induce oxidative stress and oxidative DNA damage: relevance to the pathogenesis of Barrett's oesophagus. Gut 56, 763-771. doi: 10.1136/gut.2006.103697

Eda, A., Osawa, H., Satoh, K., Yanaka, I., Kihira, K., Ishino, Y., et al. (2003). Aberrant expression of CDX2 in Barrett's epithelium and inflammatory esophageal mucosa. J. Gastroenterol. 38, 14-22. doi: 10.1007/s005350300001

Enzinger, P. C., and Mayer, R. J. (2003). Esophageal cancer. N. Engl. J. Med. 349, 2241-2252. doi: 10.1056/NEJMra035010

Eusebi, L. H., Fuccio, L., and Bazzoli, F. (2012). The role of obesity in gastroesophageal reflux disease and Barrett's esophagus. Dig. Dis. 30, 154-157. doi: $10.1159 / 000336668$

Farhadi, A., Fields, J., Banan, A., and Keshavarzian, A. (2002). Reactive oxygen species: are they involved in the pathogenesis of GERD, Barrett's esophagus, and the latter's progression toward esophageal cancer? Am. J. Gastroenterol. 97, 22-26. doi: 10.1111/j.1572-0241.2002.05444.x

Fields, G. B. (2019). The rebirth of matrix metalloproteinase inhibitors: moving beyond the dogma. Cells 8:984. doi: 10.3390/cells8090984
Fitzgerald, R. C., Abdalla, S., Onwuegbusi, B. A., Sirieix, P., Saeed, I. T., Burnham, W. R., et al. (2002). Inflammatory gradient in Barrett's oesophagus: implications for disease complications. Gut 51, 316-322. doi: 10.1136/gut.51.3.316

Folkman, J. (1971). Tumor angiogenesis: therapeutic implications. N. Engl. J. Med. 285, 1182-1186. doi: 10.1056/nejm197111182852108

Fu, L., Zhang, C., Zhang, L. Y., Dong, S. S., Lu, L. H., Chen, J., et al. (2011). Wnt2 secreted by tumour fibroblasts promotes tumour progression in oesophageal cancer by activation of the Wnt/ $\beta$-catenin signalling pathway. Gut 60,1635 1643. doi: 10.1136/gut.2011.241638

Fuchs, C. S., Shitara, K., Di Bartolomeo, M., Lonardi, S., Al-Batran, S. E., Van Cutsem, E., et al. (2019). Ramucirumab with cisplatin and fluoropyrimidine as first-line therapy in patients with metastatic gastric or junctional adenocarcinoma (RAINFALL): a double-blind, randomised, placebo-controlled, phase 3 trial. Lancet Oncol. 20, 420-435. doi: 10.1016/s1470-2045(18)30791-5

Greer, K. B., Thompson, C. L., Brenner, L., Bednarchik, B., Dawson, D., Willis, J., et al. (2012). Association of insulin and insulin-like growth factors with Barrett's oesophagus. Gut 61, 665-672. doi: 10.1136/gutjnl-2011-300641

Groblewska, M., Mroczko, B., Sosnowska, D., and Szmitkowski, M. (2012a). Interleukin 6 and C-reactive protein in esophageal cancer. Clin. Chim. Acta 413, 1583-1590. doi: 10.1016/j.cca.2012.05.009

Groblewska, M., Siewko, M., Mroczko, B., and Szmitkowski, M. (2012b). The role of matrix metalloproteinases (MMPs) and their inhibitors (TIMPs) in the development of esophageal cancer. Folia Histochem. Cytobiol. 50, 12-19. doi: $10.2478 / 18691$

Gu, Z. D., Li, J. Y., Li, M., Gu, J., Shi, X. T., Ke, Y., et al. (2005). Matrix metalloproteinases expression correlates with survival in patients with esophageal squamous cell carcinoma. Am. J. Gastroenterol. 100, 1835-1843. doi: 10.1111/j.1572-0241.2005.50018.x

Guo, X., Wang, Y., Zhang, H., Qin, C., Cheng, A., Liu, J., et al. (2020). Identification of the prognostic value of immune-related genes in esophageal cancer. Front. Genet. 11:989. doi: 10.3389/fgene.2020.00989

Han, P., Cao, P., Hu, S., Kong, K., Deng, Y., Zhao, B., et al. (2020). Esophageal microenvironment: from precursor microenvironment to premetastatic niche. Cancer Manag. Res. 12, 5857-5879. doi: 10.2147/cmar.S258215

Haque, S., and Morris, J. C. (2017). Transforming growth factor- $\beta$ : a therapeutic target for cancer. Hum. Vaccin. Immunother. 13, 1741-1750. doi: 10.1080/ 21645515.2017.1327107

Hodge, D. R., Hurt, E. M., and Farrar, W. L. (2005). The role of IL-6 and STAT3 in inflammation and cancer. Eur. J. Cancer 41, 2502-2512. doi: 10.1016/j.ejca. 2005.08.016

Hoshiba, T., and Tanaka, M. (2016). Decellularized matrices as in vitro models of extracellular matrix in tumor tissues at different malignant levels: mechanism of 5-fluorouracil resistance in colorectal tumor cells. Biochim. Biophys. Acta 1863, 2749-2757. doi: 10.1016/j.bbamcr.2016.08.009

Huang, J., Xiao, J., Fang, W., Lu, P., Fan, Q., Shu, Y., et al. (2021). Anlotinib for previously treated advanced or metastatic esophageal squamous cell carcinoma: a double-blind randomized phase 2 trial. Cancer Med. 10, 1681-1689. doi: $10.1002 / \mathrm{cam} 4.3771$

Huang, J., Xu, B., Mo, H., Zhang, W., Chen, X., Wu, D., et al. (2018). Safety, activity, and biomarkers of SHR-1210, an Anti-PD-1 antibody, for patients with advanced esophageal carcinoma. Clin. Cancer Res. 24, 1296-1304. doi: 10.1158/1078-0432.Ccr-17-2439

Huang, T. X., and Fu, L. (2019). The immune landscape of esophageal cancer. Cancer Commun. (Lond.) 39:79. doi: 10.1186/s40880-019-0427-z

Izzo, J. G., Correa, A. M., Wu, T. T., Malhotra, U., Chao, C. K., Luthra, R., et al. (2006). Pretherapy nuclear factor-kappaB status, chemoradiation resistance, and metastatic progression in esophageal carcinoma. Mol. Cancer Ther. 5, 2844-2850. doi: 10.1158/1535-7163.Mct-06-0351

Izzo, J. G., Malhotra, U., Wu, T. T., Luthra, R., Correa, A. M., Swisher, S. G. et al. (2007). Clinical biology of esophageal adenocarcinoma after surgery is influenced by nuclear factor-kappaB expression. Cancer Epidemiol. Biomarkers Prev. 16, 1200-1205. doi: 10.1158/1055-9965.Epi-06-1083

Izzo, J. G., Wu, X., Wu, T. T., Huang, P., Lee, J. S., Liao, Z., et al. (2009). Therapy-induced expression of NF-kappaB portends poor prognosis in patients with localized esophageal cancer undergoing preoperative chemoradiation. Dis. Esophagus. 22, 127-132. doi: 10.1111/j.1442-2050.2008.00884.x 
Janjigian, Y. Y., Vakiani, E., Ku, G. Y., Herrera, J. M., Tang, L. H., Bouvier, N., et al. (2015). Phase II trial of sorafenib in patients with chemotherapy refractory metastatic esophageal and gastroesophageal (ge) junction cancer. PLoS One 10:e0134731. doi: 10.1371/journal.pone.0134731

Jena, P. V., Shamay, Y., Shah, J., Roxbury, D., Paknejad, N., and Heller, D. A. (2016). Photoluminescent carbon nanotubes interrogate the permeability of multicellular tumor spheroids. Carbon N. Y. 97, 99-109. doi: 10.1016/j.carbon. 2015.08.024

Jomrich, G., Jesch, B., Birner, P., Schwameis, K., Paireder, M., Asari, R., et al. (2014). Stromal expression of carbonic anhydrase IX in esophageal cancer. Clin. Transl. Oncol. 16, 966-972. doi: 10.1007/s12094-014-1180-z

Jones, R. L., Ratain, M. J., O’Dwyer, P. J., Siu, L. L., Jassem, J., Medioni, J., et al. (2019). Phase II randomised discontinuation trial of brivanib in patients with advanced solid tumours. Eur. J. Cancer 120, 132-139. doi: 10.1016/j.ejca.2019. 07.024

Kageyama, S., Wada, H., Muro, K., Niwa, Y., Ueda, S., Miyata, H., et al. (2013). Dose-dependent effects of NY-ESO-1 protein vaccine complexed with cholesteryl pullulan (CHP-NY-ESO-1) on immune responses and survival benefits of esophageal cancer patients. J. Transl. Med. 11:246. doi: 10.1186/14795876-11-246

Kagoya, Y., Tanaka, S., Guo, T., Anczurowski, M., Wang, C. H., Saso, K., et al. (2018). A novel chimeric antigen receptor containing a JAK-STAT signaling domain mediates superior antitumor effects. Nat. Med. 24, 352-359. doi: 10. 1038/nm.4478

Kai, F., Drain, A. P., and Weaver, V. M. (2019). The extracellular matrix modulates the metastatic journey. Dev. Cell 49, 332-346. doi: 10.1016/j.devcel.2019.03.026

Kaifi, J. T., Yekebas, E. F., Schurr, P., Obonyo, D., Wachowiak, R., Busch, P., et al. (2005). Tumor-cell homing to lymph nodes and bone marrow and CXCR4 expression in esophageal cancer. J. Natl. Cancer Inst. 97, 1840-1847. doi: 10. 1093/jnci/dji431

Kalikawe, R., Baba, Y., Nomoto, D., Okadome, K., Miyake, K., Eto, K., et al. (2019). Lysyl oxidase impacts disease outcomes and correlates with global DNA hypomethylation in esophageal cancer. Cancer Sci. 110, 3727-3737. doi: 10. $1111 /$ cas. 14214

Kamat, P., Wen, S., Morris, J., and Anandasabapathy, S. (2009). Exploring the association between elevated body mass index and Barrett's esophagus: a systematic review and meta-analysis. Ann. Thorac. Surg. 87, 655-662. doi: 10. 1016/j.athoracsur.2008.08.003

Kantoff, P. W., Higano, C. S., Shore, N. D., Berger, E. R., Small, E. J., Penson, D. F., et al. (2010). Sipuleucel-T immunotherapy for castration-resistant prostate cancer. N. Engl. J. Med. 363, 411-422. doi: 10.1056/NEJMoa1001294

Karin, M., Cao, Y., Greten, F. R., and Li, Z. W. (2002). NF-kappaB in cancer: from innocent bystander to major culprit. Nat. Rev. Cancer 2, 301-310. doi: $10.1038 /$ nrc780

Kashima, H., Noma, K., Ohara, T., Kato, T., Katsura, Y., Komoto, S., et al. (2019). Cancer-associated fibroblasts (CAFs) promote the lymph node metastasis of esophageal squamous cell carcinoma. Int. J. Cancer 144, 828-840. doi: 10.1002/ ijc. 31953

Kastelein, F., Spaander, M. C., Steyerberg, E. W., Biermann, K., Valkhoff, V. E., Kuipers, E. J., et al. (2013). Proton pump inhibitors reduce the risk of neoplastic progression in patients with Barrett's esophagus. Clin. Gastroenterol. Hepatol. 11, 382-388. doi: 10.1016/j.cgh.2012.11.014

Kato, Y., Maeda, T., Suzuki, A., and Baba, Y. (2018). Cancer metabolism: new insights into classic characteristics. Jpn. Dent. Sci. Rev. 54, 8-21. doi: 10.1016/j. jdsr.2017.08.003

Katsube, R., Noma, K., Ohara, T., Nishiwaki, N., Kobayashi, T., Komoto, S., et al. (2021). Fibroblast activation protein targeted near infrared photoimmunotherapy (NIR PIT) overcomes therapeutic resistance in human esophageal cancer. Sci. Rep. 11:1693. doi: 10.1038/s41598-021-81465-4

Kiesgen, S., Chicaybam, L., Chintala, N. K., and Adusumilli, P. S. (2018). Chimeric antigen receptor (CAR) T-cell therapy for thoracic malignancies. J. Thorac. Oncol. 13, 16-26. doi: 10.1016/j.jtho.2017.10.001

Kojima, T., Shah, M. A., Muro, K., Francois, E., Adenis, A., Hsu, C. H., et al. (2020). Randomized phase III KEYNOTE-181 study of pembrolizumab versus chemotherapy in advanced esophageal cancer. J. Clin. Oncol. 38, 4138-4148. doi: $10.1200 /$ jco. 20.01888

Kono, K., Iinuma, H., Akutsu, Y., Tanaka, H., Hayashi, N., Uchikado, Y., et al. (2012). Multicenter, phase II clinical trial of cancer vaccination for advanced esophageal cancer with three peptides derived from novel cancer-testis antigens. J. Transl. Med. 10:141. doi: 10.1186/1479-5876-10-141

Krummel, M. F., and Allison, J. P. (1995). CD28 and CTLA-4 have opposing effects on the response of T cells to stimulation. J. Exp. Med. 182, 459-465. doi: 10.1084/jem.182.2.459

Kubo, N., Morita, M., Nakashima, Y., Kitao, H., Egashira, A., Saeki, H., et al. (2014). Oxidative DNA damage in human esophageal cancer: clinicopathological analysis of 8-hydroxydeoxyguanosine and its repair enzyme. Dis. Esophagus. 27, 285-293. doi: 10.1111/dote.12107

Kuroda, S., Fujiwara, T., Shirakawa, Y., Yamasaki, Y., Yano, S., Uno, F., et al. (2010). Telomerase-dependent oncolytic adenovirus sensitizes human cancer cells to ionizing radiation via inhibition of DNA repair machinery. Cancer Res. 70, 9339-9348. doi: 10.1158/0008-5472.Can-10-2333

Kwon, J., Lee, T. S., Lee, H. W., Kang, M. C., Yoon, H. J., Kim, J. H., et al. (2013). Integrin alpha 6: a novel therapeutic target in esophageal squamous cell carcinoma. Int. J. Oncol. 43, 1523-1530. doi: 10.3892/ijo.2013.2097

Ladeira, K., Macedo, F., Longatto-Filho, A., and Martins, S. F. (2018). Angiogenic factors: role in esophageal cancer, a brief review. Esophagus 15, 53-58. doi: 10.1007/s10388-017-0597-1

Lee, J. S., and Ruppin, E. (2019). Multiomics prediction of response rates to therapies to inhibit programmed cell death 1 and programmed cell death 1 ligand 1. JAMA Oncol. 5, 1614-1618. doi: 10.1001/jamaoncol.2019.2311

Lei, Z., Jian, M., Li, X., Wei, J., Meng, X., and Wang, Z. (2020). Biosensors and bioassays for determination of matrix metalloproteinases: state of the art and recent advances. J. Mater. Chem. B 8, 3261-3291. doi: 10.1039/c9tb02189b

Li, J., Jia, Y., Gao, Y., Chang, Z., Han, H., Yan, J., et al. (2019). Clinical efficacy and survival analysis of apatinib combined with docetaxel in advanced esophageal cancer. Onco. Targets Ther. 12, 2577-2583. doi: 10.2147/ott.S191736

Li, L., Wei, J. R., Dong, J., Lin, Q. G., Tang, H., Jia, Y. X., et al. (2021). Laminin $\gamma 2$ mediating $\mathrm{T}$ cell exclusion attenuates response to anti-PD-1 therapy. Sci. Adv. 7:eabc8346. doi: 10.1126/sciadv.abc8346

Li, Y., Sui, H., Jiang, C., Li, S., Han, Y., Huang, P., et al. (2018). Dihydroartemisinin increases the sensitivity of photodynamic therapy via NF- $\mathrm{B} / \mathrm{HIF}-1 \alpha /$ VEGF pathway in esophageal cancer cell in vitro and in vivo. Cell Physiol. Biochem. 48, 2035-2045. doi: 10.1159/000492541

Liao, X., Gao, Y., Liu, J., Tao, L., Xie, J., Gu, Y., et al. (2020). Combination of tanshinone IIA and cisplatin inhibits esophageal cancer by downregulating NF-кB/COX-2/VEGF pathway. Front. Oncol. 10:1756. doi: 10.3389/fonc.2020. 01756

Lin, E. W., Karakasheva, T. A., Hicks, P. D., Bass, A. J., and Rustgi, A. K. (2016). The tumor microenvironment in esophageal cancer. Oncogene 35, 5337-5349. doi: 10.1038 /onc. 2016.34

Liu, G., Chen, T., Ding, Z., Wang, Y., Wei, Y., and Wei, X. (2021). Inhibition of FGF-FGFR and VEGF-VEGFR signalling in cancer treatment. Cell Prolif. 54:e13009. doi: 10.1111/cpr.13009

Liu, G., Wang, Y., Wang, C., He, Y., and E M. (2020). Clinical efficacy and safety of apatinib as maintenance treatment in patients with advanced esophageal squamous cell carcinoma. Expert. Rev. Clin. Pharmacol. 13, 1423-1430. doi: 10.1080/17512433.2020.1844004

Liu, J., Gao, J., Zhang, A., Guo, Y., Fan, S., He, Y., et al. (2020). Carbon nanocagebased nanozyme as an endogenous $\mathrm{H}(2) \mathrm{O}(2)$-activated oxygenerator for realtime bimodal imaging and enhanced phototherapy of esophageal cancer. Nanoscale 12, 21674-21686. doi: 10.1039/d0nr05945e

Lord, R. V., Park, J. M., Wickramasinghe, K., DeMeester, S. R., Oberg, S., Salonga, D., et al. (2003). Vascular endothelial growth factor and basic fibroblast growth factor expression in esophageal adenocarcinoma and Barrett esophagus. J. Thorac. Cardiovasc. Surg. 125, 246-253. doi: 10.1067/mtc.2003.203

Loriot, Y., Necchi, A., Park, S. H., Garcia-Donas, J., Huddart, R., Burgess, E., et al. (2019). Erdafitinib in locally advanced or metastatic urothelial carcinoma. N. Engl. J. Med. 381, 338-348. doi: 10.1056/NEJMoa1817323

Luan, S., Zeng, X., Zhang, C., Qiu, J., Yang, Y., Mao, C., et al. (2021). Advances in drug resistance of esophageal cancer: from the perspective of tumor microenvironment. Front. Cell Dev. Biol. 9:664816. doi: 10.3389/fcell.2021. 664816

Ma, J., Zhao, J., Lu, J., Jiang, Y., Yang, H., Li, P., et al. (2012). Coxsackievirus and adenovirus receptor promotes antitumor activity of oncolytic adenovirus $\mathrm{H} 101$ in esophageal cancer. Int. J. Mol. Med. 30, 1403-1409. doi: 10.3892/ijmm.2012. 1133 
Maeda, Y., Takeuchi, H., Matsuda, S., Okamura, A., Fukuda, K., Miyasho, T., et al. (2020). Clinical significance of preoperative serum concentrations of interleukin-6 as a prognostic marker in patients with esophageal cancer. Esophagus 17, 279-288. doi: 10.1007/s10388-019-00708-6

Masoud, G. N., and Li, W. (2015). HIF-1 $\alpha$ pathway: role, regulation and intervention for cancer therapy. Acta Pharm. Sin. B 5, 378-389. doi: 10.1016/ j.apsb.2015.05.007

Mitsunaga, M., Ogawa, M., Kosaka, N., Rosenblum, L. T., Choyke, P. L., and Kobayashi, H. (2011). Cancer cell-selective in vivo near infrared photoimmunotherapy targeting specific membrane molecules. Nat. Med. 17, 1685-1691. doi: 10.1038/nm.2554

Moehler, M., Gepfner-Tuma, I., Maderer, A., Thuss-Patience, P. C., Ruessel, J., Hegewisch-Becker, S., et al. (2016). Sunitinib added to FOLFIRI versus FOLFIRI in patients with chemorefractory advanced adenocarcinoma of the stomach or lower esophagus: a randomized, placebo-controlled phase II AIO trial with serum biomarker program. BMC Cancer 16:699. doi: 10.1186/s12885-0162736-9

Mokrowiecka, A., Daniel, P., Jasinska, A., Pietruczuk, M., Pawlowski, M., Szczesniak, P., et al. (2012). Serum adiponectin, resistin, leptin concentration and central adiposity parameters in Barrett's esophagus patients with and without intestinal metaplasia in comparison to healthy controls and patients with GERD. Hepatogastroenterology 59, 2395-2399. doi: 10.5754/hge12587

Nabeki, B., Ishigami, S., Uchikado, Y., Sasaki, K., Kita, Y., Okumura, H., et al. (2015). Interleukin-32 expression and Treg infiltration in esophageal squamous cell carcinoma. Anticancer Res. 35, 2941-2947.

Nguyen, D. M., El-Serag, H. B., Henderson, L., Stein, D., Bhattacharyya, A., and Sampliner, R. E. (2009). Medication usage and the risk of neoplasia in patients with Barrett's esophagus. Clin. Gastroenterol. Hepatol. 7, 1299-1304. doi: 10. 1016/j.cgh.2009.06.001

Nguyen, M. P., Lee, S., and Lee, Y. M. (2013). Epigenetic regulation of hypoxia inducible factor in diseases and therapeutics. Arch. Pharm. Res. 36, 252-263. doi: 10.1007/s12272-013-0058-x

Nie, L., Lyros, O., Medda, R., Jovanovic, N., Schmidt, J. L., Otterson, M. F., et al. (2014). Endothelial-mesenchymal transition in normal human esophageal endothelial cells cocultured with esophageal adenocarcinoma cells: role of IL-1 $\beta$ and TGF- $\beta 2$. Am. J. Physiol. Cell Physiol. 307, C859-C877. doi: 10.1152/ajpcell. 00081.2014

Ogura, M., Takeuchi, H., Kawakubo, H., Nishi, T., Fukuda, K., Nakamura, R., et al. (2013). Clinical significance of CXCL-8/CXCR-2 network in esophageal squamous cell carcinoma. Surgery 154, 512-520. doi: 10.1016/j.surg.2013.06. 013

Ohashi, S., Miyamoto, S., Kikuchi, O., Goto, T., Amanuma, Y., and Muto, M. (2015). Recent advances from basic and clinical studies of esophageal squamous cell carcinoma. Gastroenterology 149, 1700-1715. doi: 10.1053/j.gastro.2015.08. 054

Ohigashi, Y., Sho, M., Yamada, Y., Tsurui, Y., Hamada, K., Ikeda, N., et al. (2005). Clinical significance of programmed death-1 ligand-1 and programmed death-1 ligand-2 expression in human esophageal cancer. Clin. Cancer Res. 11, 2947-2953. doi: 10.1158/1078-0432.Ccr-04-1469

Oka, M., Iizuka, N., Yamamoto, K., Gondo, T., Abe, T., Hazama, S., et al. (1996). The influence of interleukin-6 on the growth of human esophageal cancer cell lines. J. Interferon. Cytokine Res. 16, 1001-1006. doi: 10.1089/jir.1996.16. 1001

Olsson, A. K., Dimberg, A., Kreuger, J., and Claesson-Welsh, L. (2006). VEGF receptor signalling - in control of vascular function. Nat. Rev. Mol. Cell Biol. 7, 359-371. doi: 10.1038/nrm1911

Paget, S. (1989). The distribution of secondary growths in cancer of the breast. 1889. Cancer Metastasis Rev. 8, 98-101.

Palumbo, A. Jr., Meireles Da Costa, N., Pontes, B., Leite, de Oliveira, F., Lohan Codeço, M., et al. (2020). Esophageal cancer development: crucial clues arising from the extracellular matrix. Cells 9:455. doi: 10.3390/cells9020455

Pan, P., Yang, B. X., and Ge, X. L. (2018). Brucea javanica seed oil enhances the radiosensitivity of esophageal cancer by inhibiting hypoxia-inducible factor $1 \alpha$, in vitro and in vivo. Oncol. Lett. 15, 3870-3875. doi: 10.3892/ol.2018.7779

Piperigkou, Z., Kyriakopoulou, K., Koutsakis, C., Mastronikolis, S., and Karamanos, N. K. (2021). Key matrix remodeling enzymes: functions and targeting in cancer. Cancers (Basel) 13:1441. doi: 10.3390/cancers13061441
Polyak, K., Haviv, I., and Campbell, I. G. (2009). Co-evolution of tumor cells and their microenvironment. Trends Genet. 25, 30-38. doi: 10.1016/j.tig.2008.10. 012

Poulsen, H. E., Prieme, H., and Loft, S. (1998). Role of oxidative DNA damage in cancer initiation and promotion. Eur. J. Cancer Prev. 7, 9-16.

Radojicic, J., Zaravinos, A., and Spandidos, D. A. (2012). HPV, KRAS mutations, alcohol consumption and tobacco smoking effects on esophageal squamous-cell carcinoma carcinogenesis. Int. J. Biol. Markers 27, 1-12. doi: 10.5301/jbm.2011. 8737

Rafiee, P., Nelson, V. M., Manley, S., Wellner, M., Floer, M., Binion, D. G., et al. (2009). Effect of curcumin on acidic pH-induced expression of IL-6 and IL8 in human esophageal epithelial cells (HET-1A): role of PKC, MAPKs, and NF-kappaB. Am. J. Physiol. Gastrointest. Liver Physiol. 296, G388-G398. doi: 10.1152/ajpgi.90428.2008

Ralph, C., Elkord, E., Burt, D. J., O’Dwyer, J. F., Austin, E. B., Stern, P. L., et al. (2010). Modulation of lymphocyte regulation for cancer therapy: a phase II trial of tremelimumab in advanced gastric and esophageal adenocarcinoma. Clin. Cancer Res. 16, 1662-1672. doi: 10.1158/1078-0432.Ccr-09-2870

Rieder, F., Cheng, L., Harnett, K. M., Chak, A., Cooper, G. S., Isenberg, G., et al. (2007). Gastroesophageal reflux disease-associated esophagitis induces endogenous cytokine production leading to motor abnormalities. Gastroenterology 132, 154-165. doi: 10.1053/j.gastro.2006.10.009

Roskoski, R. Jr. (2007). Vascular endothelial growth factor (VEGF) signaling in tumor progression. Crit. Rev. Oncol. Hematol. 62, 179-213. doi: 10.1016/j. critrevonc.2007.01.006

Rustgi, A. K., and El-Serag, H. B. (2014). Esophageal carcinoma. N. Engl. J. Med. 371, 2499-2509. doi: 10.1056/NEJMra1314530

Sadanaga, N., Nagashima, H., Mashino, K., Tahara, K., Yamaguchi, H., Ohta, M., et al. (2001). Dendritic cell vaccination with MAGE peptide is a novel therapeutic approach for gastrointestinal carcinomas. Clin. Cancer Res. 7, 2277-2284.

Schmitt, J. M., Sommers, S. R., Fisher, W., Ansari, R., Robin, E., Koneru, K., et al. (2012). Sunitinib plus paclitaxel in patients with advanced esophageal cancer: a phase II study from the Hoosier Oncology Group. J. Thorac. Oncol. 7, 760-763. doi: 10.1097/JTO.0b013e31824abc7c

Shah, M. A., Cho, J. Y., Tan, I. B., Tebbutt, N. C., Yen, C. J., Kang, A., et al. (2016). A randomized phase II study of folfox with or without the MET inhibitor onartuzumab in advanced adenocarcinoma of the stomach and gastroesophageal junction. Oncologist 21, 1085-1090. doi: 10.1634/ theoncologist.2016-0038

Shen, Y., Xie, S., Zhao, L., Song, G., Shao, Y., Hao, C., et al. (2020). Estimating individualized absolute risk for esophageal squamous cell carcinoma: a population-based study in high-risk areas of china. Front. Oncol. 10:598603. doi: $10.3389 /$ fonc. 2020.598603

Shi, H., Yu, F., Mao, Y., Ju, Q., Wu, Y., Bai, W., et al. (2018). EphA2 chimeric antigen receptor-modified $\mathrm{T}$ cells for the immunotherapy of esophageal squamous cell carcinoma. J. Thorac. Dis. 10, 2779-2788. doi: 10.21037/jtd.2018. 04.91

Shigeoka, M., Urakawa, N., Nakamura, T., Nishio, M., Watajima, T., Kuroda, D., et al. (2013). Tumor associated macrophage expressing CD204 is associated with tumor aggressiveness of esophageal squamous cell carcinoma. Cancer Sci. 104, 1112-1119. doi: 10.1111/cas. 12188

Smyth, E. C., Gambardella, V., Cervantes, A., and Fleitas, T. (2021). Checkpoint inhibitors for gastroesophageal cancers: dissecting heterogeneity to better understand their role in first line and adjuvant therapy. Ann. Oncol. 32, 590-599. doi: 10.1016/j.annonc.2021.02.004

Smyth, E. C., Lagergren, J., Fitzgerald, R. C., Lordick, F., Shah, M. A., Lagergren, P., et al. (2017). Oesophageal cancer. Nat. Rev. Dis. Primers 3:17048. doi: 10.1038/ nrdp. 2017.48

Sormendi, S., and Wielockx, B. (2018). Hypoxia pathway proteins as central mediators of metabolism in the tumor cells and their microenvironment. Front. Immunol. 9:40. doi: 10.3389/fimmu.2018.00040

Sun, W., Powell, M., O’Dwyer, P. J., Catalano, P., Ansari, R. H., and Benson, A. B. III (2010). Phase II study of sorafenib in combination with docetaxel and cisplatin in the treatment of metastatic or advanced gastric and gastroesophageal junction adenocarcinoma: ECOG 5203. J. Clin. Oncol. 28, 2947-2951. doi: 10.1200/jco.2009.27.7988 
Sung, S. Y., and Chung, L. W. (2002). Prostate tumor-stroma interaction: molecular mechanisms and opportunities for therapeutic targeting. Differentiation 70 , 506-521. doi: 10.1046/j.1432-0436.2002.700905.x

Suzuki, T., Ishibashi, Y., Tsujimoto, H., Nomura, S., Kouzu, K., Itazaki, Y., et al. (2020). A novel systemic inflammatory score combined with immunoinflammatory markers accurately reflects prognosis in patients with esophageal cancer. In Vivo 34, 3705-3711. doi: 10.21873/ invivo. 12218

Takada, N., Yano, Y., Matsuda, T., Otani, S., Osugi, H., Higashino, M., et al. (1995). Expression of immunoreactive human hepatocyte growth factor in human esophageal squamous cell carcinomas. Cancer Lett. 97, 145-148. doi: 10.1016/0304-3835(95)03967-2

Topalian, S. L., Hodi, F. S., Brahmer, J. R., Gettinger, S. N., Smith, D. C., McDermott, D. F., et al. (2012). Safety, activity, and immune correlates of anti-PD-1 antibody in cancer. N. Engl. J. Med. 366, 2443-2454. doi: 10.1056/ NEJMoa1200690

Torre, L. A., Bray, F., Siegel, R. L., Ferlay, J., Lortet-Tieulent, J., and Jemal, A. (2015). Global cancer statistics, 2012. CA Cancer J. Clin. 65, 87-108. doi: 10.3322/caac. 21262

U.S. National Library of Medicine (2021a). Available online at: https://clinicaltrials. gov/ct2/show/NCT03274011?term $=$ NCT03274011\&draw $=2 \&$ rank $=1$ (accessed January 26, 2021).

U.S. National Library of Medicine (2021b). Available online at: https://clinicaltrials. gov/ct2/show/NCT03797625?term =NCT03797625\&draw $=2 \&$ rank $=1$ (accessed January 9, 2019).

Ueno, N., Shimizu, A., Kanai, M., Iwaya, Y., Ueda, S., Nakayama, J., et al. (2016). Enhanced expression of fibroblast growth factor receptor 3 iiic promotes human esophageal carcinoma cell proliferation. J. Histochem. Cytochem. 64, 7-17. doi: 10.1369/0022155415616161

Underwood, T. J., Hayden, A. L., Derouet, M., Garcia, E., Noble, F., White, M. J., et al. (2015). Cancer-associated fibroblasts predict poor outcome and promote periostin-dependent invasion in oesophageal adenocarcinoma. J. Pathol. 235, 466-477. doi: 10.1002/path.4467

Van Cutsem, E., Karaszewska, B., Kang, Y. K., Chung, H. C., Shankaran, V., Siena, S., et al. (2019). A multicenter phase II study of amg 337 in patients with MET-amplified gastric/gastroesophageal junction/esophageal adenocarcinoma and other MET-amplified solid tumors. Clin. Cancer Res. 25, 2414-2423. doi: 10.1158/1078-0432.Ccr-18-1337

Van der Veldt, A. A., Lubberink, M., Bahce, I., Walraven, M., de Boer, M. P., Greuter, H. N., et al. (2012). Rapid decrease in delivery of chemotherapy to tumors after anti-VEGF therapy: implications for scheduling of anti-angiogenic drugs. Cancer Cell 21, 82-91. doi: 10.1016/j.ccr.2011.11.023

Vander Heiden, M. G., Cantley, L. C., and Thompson, C. B. (2009). Understanding the warburg effect: the metabolic requirements of cell proliferation. Science 324, 1029-1033. doi: 10.1126/science. 1160809

von Rahden, B. H., Stein, H. J., Feith, M., Pühringer, F., Theisen, J., Siewert, J. R., et al. (2006). Overexpression of TGF-betal in esophageal (Barrett's) adenocarcinoma is associated with advanced stage of disease and poor prognosis. Mol. Carcinog. 45, 786-794. doi: 10.1002/mc.20259

Walker, M. M., and Talley, N. J. (2014). Review article: bacteria and pathogenesis of disease in the upper gastrointestinal tract-beyond the era of Helicobacter pylori. Aliment. Pharmacol. Ther. 39, 767-779. doi: 10.1111/apt.12666

Wang, B., Zhao, Q., Zhang, Y., Liu, Z., Zheng, Z., Liu, S., et al. (2021). Targeting hypoxia in the tumor microenvironment: a potential strategy to improve cancer immunotherapy. J. Exp. Clin. Cancer Res. 40:24. doi: 10.1186/s13046-02001820-7

Wang, D. H., Clemons, N. J., Miyashita, T., Dupuy, A. J., Zhang, W., Szczepny, A., et al. (2010). Aberrant epithelial-mesenchymal Hedgehog signaling characterizes Barrett's metaplasia. Gastroenterology 138, 1810-1822. doi: 10. 1053/j.gastro.2010.01.048

Wang, D., Qin, Q., Jiang, Q. J., and Wang, D. F. (2016). Bortezomib sensitizes esophageal squamous cancer cells to radiotherapy by suppressing the expression of HIF-1 $\alpha$ and apoptosis proteins. J. Xray Sci. Technol. 24, 639-646. doi: 10. 3233/xst- 160571

Wang, H., Rao, B., Lou, J., Li, J., Liu, Z., Li, A., et al. (2020). The Function of the HGF/c-met axis in hepatocellular carcinoma. Front. Cell Dev. Biol. 8:55. doi: $10.3389 /$ fcell.2020.00055
Wang, L., Han, H., Dong, L., Wang, Z., and Qin, Y. (2021). Function of p21 and its therapeutic effects in esophageal cancer. Oncol. Lett. 21:136. doi: 10.3892/ol. 2020.12397

Wang, T., Niu, G., Kortylewski, M., Burdelya, L., Shain, K., Zhang, S., et al. (2004). Regulation of the innate and adaptive immune responses by Stat-3 signaling in tumor cells. Nat. Med. 10, 48-54. doi: 10.1038/nm976

Weber, J. S., D’Angelo, S. P., Minor, D., Hodi, F. S., Gutzmer, R., Neyns, B., et al. (2015). Nivolumab versus chemotherapy in patients with advanced melanoma who progressed after anti-CTLA-4 treatment (CheckMate 037): a randomised, controlled, open-label, phase 3 trial. Lancet Oncol. 16, 375-384. doi: 10.1016/ s1470-2045(15)70076-8

Whiteside, T. L. (2008). The tumor microenvironment and its role in promoting tumor growth. Oncogene 27, 5904-5912. doi: 10.1038/onc.2008.271

Wigerup, C., Påhlman, S., and Bexell, D. (2016). Therapeutic targeting of hypoxia and hypoxia-inducible factors in cancer. Pharmacol. Ther. 164, 152-169. doi: 10.1016/j.pharmthera.2016.04.009

Wilke, H., Muro, K., Van Cutsem, E., Oh, S. C., Bodoky, G., Shimada, Y., et al. (2014). Ramucirumab plus paclitaxel versus placebo plus paclitaxel in patients with previously treated advanced gastric or gastro-oesophageal junction adenocarcinoma (RAINBOW): a double-blind, randomised phase 3 trial. Lancet Oncol. 15, 1224-1235. doi: 10.1016/s1470-2045(14)70420-6

Wojtowicz-Praga, S. (2003). Reversal of tumor-induced immunosuppression by TGF-beta inhibitors. Invest. New Drugs 21, 21-32. doi: 10.1023/a: 1022951824806

Wu, C., Mikhail, S., Wei, L., Timmers, C., Tahiri, S., Neal, A., et al. (2015). A phase II and pharmacodynamic study of sunitinib in relapsed/refractory oesophageal and gastro-oesophageal cancers. Br. J. Cancer 113, 220-225. doi: 10.1038/bjc. 2015.197

Wu, H., Chen, S., Yu, J., Li, Y., Zhang, X. Y., Yang, L., et al. (2018). Singlecell transcriptome analyses reveal molecular signals to intrinsic and acquired paclitaxel resistance in esophageal squamous cancer cells. Cancer Lett. 420, 156-167. doi: 10.1016/j.canlet.2018.01.059

Xiang, Q., Qiao, B., Luo, Y., Cao, J., Fan, K., Hu, X., et al. (2021). Increased photodynamic therapy sensitization in tumors using a nitric oxide-based nanoplatform with ATP-production blocking capability. Theranostics 11, 19531969. doi: 10.7150/thno.52997

Xiaoyu, H., Yiru, Y., Shuisheng, S., Keyan, C., Zixing, Y., Shanglin, C., et al. (2018). The mTOR pathway regulates PKM2 to affect glycolysis in esophageal squamous cell carcinoma. Technol. Cancer Res. Treat. 17:1533033818780063. doi: 10.1177/1533033818780063

Xu, J., Zhang, Y., Jia, R., Yue, C., Chang, L., Liu, R., et al. (2019). Anti-PD1 Antibody SHR-1210 combined with apatinib for advanced hepatocellular carcinoma, gastric, or esophagogastric junction cancer: an open-label, dose escalation and expansion study. Clin. Cancer Res. 25, 515-523. doi: 10.1158/ 1078-0432.Ccr-18-2484

Xu, M., Huang, H., Xiong, Y., Peng, B., Zhou, Z., Wang, D., et al. (2014). Combined chemotherapy plus endostar with sequential stereotactic radiotherapy as salvage treatment for recurrent esophageal cancer with severe dyspnea: a case report and review of the literature. Oncol. Lett. 8, 291-294. doi: 10.3892/ol.2014.2087

Yamamoto, S., and Kato, K. (2020). Immuno-oncology for esophageal cancer. Future Oncol. 16, 2673-2681. doi: 10.2217/fon-2020-0545

Yan, Z., Yao, Z. H., Yao, S. N., Wang, H. Y., Chu, J. F., Song, M., et al. (2020). Camrelizumab plus apatinib successfully treated a patient with advanced esophageal squamous cell carcinoma. Immunotherapy 12, 1161-1166. doi: 10 . 2217/imt-2020-0197

Yang, H., Wang, K., Wang, T., Li, M., Li, B., Li, S., et al. (2020). The combination options and predictive biomarkers of PD-1/PD-L1 inhibitors in esophageal cancer. Front. Oncol. 10:300. doi: 10.3389/fonc.2020.00300

Yang, L., Francois, F., and Pei, Z. (2012). Molecular pathways: pathogenesis and clinical implications of microbiome alteration in esophagitis and Barrett esophagus. Clin. Cancer Res. 18, 2138-2144. doi: 10.1158/1078-0432.Ccr-110934

Yang, Y. M., Hong, P., Xu, W. W., He, Q. Y., and Li, B. (2020). Advances in targeted therapy for esophageal cancer. Signal. Transduct. Target Ther. 5:229. doi: 10.1038/s41392-020-00323-3

Ye, W. (2016). The complexity of translating anti-angiogenesis therapy from basic science to the clinic. Dev. Cell 37, 114-125. doi: 10.1016/j.devcel.2016.03.015 
Yoon, H. H., Bendell, J. C., Braiteh, F. S., Firdaus, I., Philip, P. A., Cohn, A. L., et al. (2016). Ramucirumab combined with FOLFOX as front-line therapy for advanced esophageal, gastroesophageal junction, or gastric adenocarcinoma: a randomized, double-blind, multicenter Phase II trial. Ann. Oncol. 27, 21962203. doi: 10.1093/annonc/mdw423

Yu, F., Wang, X., Shi, H., Jiang, M., Xu, J., Sun, M., et al. (2020). Development of chimeric antigen receptor-modified $\mathrm{T}$ cells for the treatment of esophageal cancer. Tumori 107, 341-352. doi: 10.1177/0300891620960223

Yu, Y., Li, X., Xu, H., Liu, J., Dong, M., Yang, J., et al. (2018). Correlation of hypoxia status with radiosensitizing effects of sodium glycididazole: a preclinical study. Oncol. Lett. 15, 6481-6488. doi: 10.3892/ol.2018.8096

Zhang, B., Qi, L., Wang, X., Xu, J., Liu, Y., Mu, L., et al. (2020). Phase II clinical trial using camrelizumab combined with apatinib and chemotherapy as the first-line treatment of advanced esophageal squamous cell carcinoma. Cancer Commun. (Lond.) 40, 711-720. doi: 10.1002/cac2.12119

Zhang, H., Zhao, H., He, X., Xi, F., and Liu, J. (2020). JAK-STAT domain enhanced MUC1-CAR-T cells induced esophageal cancer elimination. Cancer Manag. Res. 12, 9813-9824. doi: 10.2147/cmar.S264358

Zhang, L., Xiao, X., Arnold, P. R., and Li, X. C. (2019). Transcriptional and epigenetic regulation of immune tolerance: roles of the NF- $\mathrm{B}$ family members. Cell Mol. Immunol. 16, 315-323. doi: 10.1038/s41423-019-0202-8

Zhao, S., Ren, S., Jiang, T., Zhu, B., Li, X., Zhao, C., et al. (2019). Low-dose apatinib optimizes tumor microenvironment and potentiates antitumor effect of PD-1/PD-L1 blockade in lung cancer. Cancer Immunol. Res. 7, 630-643. doi: 10.1158/2326-6066.Cir-17-0640

Zou, W., Wolchok, J. D., and Chen, L. (2016). PD-L1 (B7-H1) and PD1 pathway blockade for cancer therapy: mechanisms, response biomarkers, and combinations. Sci. Transl. Med. 8:328rv324. doi: 10.1126/scitranslmed. $\operatorname{aad} 7118$

Conflict of Interest: The authors declare that the research was conducted in the absence of any commercial or financial relationships that could be construed as a potential conflict of interest.

Publisher's Note: All claims expressed in this article are solely those of the authors and do not necessarily represent those of their affiliated organizations, or those of the publisher, the editors and the reviewers. Any product that may be evaluated in this article, or claim that may be made by its manufacturer, is not guaranteed or endorsed by the publisher.

Copyright (c) 2021 Wang, Han, Wang, Shi, Yang and Qin. This is an open-access article distributed under the terms of the Creative Commons Attribution License (CC BY). The use, distribution or reproduction in other forums is permitted, provided the original author(s) and the copyright owner(s) are credited and that the original publication in this journal is cited, in accordance with accepted academic practice. No use, distribution or reproduction is permitted which does not comply with these terms. 